\title{
LA OCUPACIÓN DE LA CUENCA DEL GUADALETE DURANTE EL PALEOLÍTICO SUPERIOR. REEVALUACIÓN Y ENMARQUE DENTRO DEL CONTEXTO DEL SUR PENINSULAR
}

\section{THE SETTLEMENT OF THE GUADALETE RIVER BASIN DURING THE UPPER PALAEOLITHIC. RE-EVALUATION WITHIN THE CONTEXT OF SOUTHERN IBERIA}

\author{
Francisco J. GILES GUZMÁN ${ }^{1 *}$, Francisco GILES PACHECO ${ }^{2 * *}$ y José María GUTIÉRREZ LÓPEZ ${ }^{3 * * *}$ \\ ${ }^{1}$ The Gibraltar National Museum. 18, 20 Bomb House Ln, Gibraltar GX11 1AA \\ ${ }^{2}$ Director jubilado del Museo Municipal de El Puerto de Santa María \\ ${ }^{3}$ Museo Histórico Municipal de Villamartín. Av. de la Feria 25, 11650, Villamartín, Cádiz, España \\ * Correo electrónico: francisco.giles@gibmuseum.gi \\ ** Correo electrónico: pacogiles@hotmail.es \\ *** Correo electrónico: museomunicipal@villamartin.es
}

Resumen: Este artículo pretende realizar una revaloración de los yacimientos del Paleolítico superior de la cuenca del Guadalete. En su mayoría fueron dados a conocer en la década de los 90 del siglo pasado, pero desde esas fechas se han añadido nuevas localizaciones, así como nuevos estudios. Dada la oportunidad de este Homenaje, creemos conveniente realizar una contextualización dentro del panorama actual de las investigaciones.

Palabras Clave: Paleolítico superior, Guadalete, Auriñaciense, Gravetiense, Solutrense, Magdaleniense.

\begin{abstract}
This article aims to carry out a re-evaluation of the Upper Palaeolithic sites of the Guadalete River basin. Most of these were made known in the 1990s, but new locations and studies have come to light since then. We have taken the opportunity, in this special edition tribute, to contextualise these within the current research panorama.
\end{abstract}

Keywords: Upper Palaeolithic, Guadalete, Aurignacian, Gravettian, Solutrean, Magdalenian.

Sumario: 1. Introducción. 2. Contexto geográfico. 3. Yacimientos al aire libre. 3.1. Las Arenosas. 3.2. La Escalera 1. 3.3. La Escalera 3. 3.4. Llanos de Don Pedro. 3.5. El Jadramil. 3.6. Los Frailes. 3.7. Barranco Blanco. 3.8. Arroyo de Matavacas. 3.9. La Toleta. 4. Yacimientos en Cueva. 4.1. Cueva de Higueral de Valleja. 5. El contexto regional del sur de la península Ibérica. 5.1. Paleolítico superior inicial: Auriñaciense y Gravetiense. 5.2. Solutrense. 5.3. Magdaleniense. 6. Conclusiones. 7. Bibliografía.

\section{Introducción}

Con este trabajo abordamos, desde una perspectiva actual, un balance e interpretación de las ocupaciones durante el Paleolítico superior en la cuenca del Guadalete, la mayoría de ellas catalogadas en la década de los 90 dentro del "Proyecto Guadalete" (Proyecto "Prospecciones arqueológicas superficiales en la cuenca del río Guadalete. Análisis geocronológicos y sedimentológicos" dirigido por Francisco Giles Pacheco con autorización de la Dirección General de BB. CC. de la Junta de Andalucía), a los que se ha sumado alguna nueva localización posterior o nuevos estudios de algunos yacimientos ya localizados, que vienen a enriquecer la perspectiva que de este periodo tenemos en este área. Enmarcamos el área del Guadalete dentro de una revisión de las ocupaciones paleolíticas del sur peninsular y enfatizamos el carácter solutrense de la mayoría de sus ocupaciones dentro de un panorama regional con características similares.

\section{Contexto geográfico}

Con un recorrido de $165 \mathrm{~km}$ y una cuenca de drenaje de $3.966 \mathrm{~km} 2$, el río Guadalete constituye la principal arteria fluvial de la provincia de Cádiz, incluyendo pequeñas áreas de las provincias de Sevilla y Málaga, constituyendo uno de los accidentes geográficos vertebradores del paisaje gaditano. En su cuenca alta, con nacimiento en la Sierra de Gra- 
zalema, se inserta dentro de un paisaje cárstico muy desarrollado, caracterizado principalmente por calizas, dolomías y margocalizas, con edades comprendidas entre el Jurásico y el Cretácico, con presencia de estratificaciones de sílex y radiolaritas. Posteriormente, abandona el relieve subbético y entra en áreas del flysch de la Unidad del Aljibe, donde afloran areniscas cuarzosas estratificadas en gruesos bancos, siendo esta zona la primera en la que se localizan las primeras formaciones de terrazas. El trazado del río continúa discurriendo por áreas de campiña de edad terciaria, Mioceno inferior-Plioceno, conformando amplios valles y vegas, con desarrollo de hasta siete niveles de terrazas fluviales desde el Pleistoceno inferior hasta el Holoceno (Zazo y Goy, 1988; Giles et al., 1992). Los sedimentos de estas se componen de gravas, arenas y en menor medida arcillas, discurriendo el cauce con un trazado meandriforme hasta su tramo final y zona de estuario dominado por la dinámica litoral de la Bahía de Cádiz. Recientes trabajos han arrojado nuevos datos sobre la posible influencia de un paleocanal del Guadalete en la morfología relicta de las islas gaditanas (Bernal et al., 2020).

A lo largo del recorrido del río Guadalete han sido muchas las localizaciones descubiertas desde su nacimiento hasta la desembocadura, abarcando una ocupación paleolítica desde el Pleistoceno medio, con industrias adscritas al Achelense, hasta el Paleolítico superior (Giles et al., 1991, 1992, 1995), objeto de nuestro trabajo. A día de hoy las ocupaciones localizadas para este periodo se encuentran emplazadas en la zona alta y media de la cuenca. Es en esta área donde, en el transcurso de las investigaciones, se han detectado yacimientos superopaleolíticos tanto al aire libre como en cueva.

\section{Yacimientos al aire libre}

Se trata de sitios localizados en depósitos secundarios de tipo glacis y coberteras de terrazas fluviales, estudiados a partir de materiales en superficie. Se encuentran en las zonas de campiña de la depresión, desde aguas abajo de Arcos de la Frontera a Villamartín, donde el río surca los niveles terciarios de Mioceno inferior-Plioceno, desarrollando un antiguo valle de entre 2 y $5 \mathrm{~km}$ de extensión con el desarrollo de las formaciones fluviales antes citadas.

\subsection{Las Arenosas}

Localizado en un glacis situado próximo a la confluencia del río Guadalete con su principal afluente, el río Majaceite (Giles et al., 1993), en el T. M. de San José del Valle (Figura 1, Tabla 1). Se haya compuesto por arenas rubefactadas, con componentes de cuarzo y niveles de cantos, cubierto a techo por mantos de arenas muy lavadas, originadas por el proceso de erosión y transporte del estrato inferior.

El conjunto industrial estudiado se localizó a techo de un nivel de arenas rojas plio-cuaternarias. Se trata de un conjunto lítico al que se añaden restos fósiles de fauna, como un individuo juvenil del género Bos sp., sumándose otros restos que no pudieron ser identificados. El conjunto lítico, sobre sílex, presenta un fuerte carácter laminar, los útiles retocados se caracterizarían por un conjunto equilibrado de raspadores sobre láminas, dobles, en abanico, sobre lascas retocadas y en hocico (Figura $2,1-7)$, junto con buriles simples, con uno o dos paños, múltiples y sobre truncadura (Figura 2 , 8-11), a lo que habría que sumar la presencia de láminas y laminitas con bordes abatidos (Figura 2,12 ), muescas y denticulados (Figura 2, 13-17). El conjunto lítico estudiado no permite una atribución tecno-cultural segura, aunque el conjunto presenta rasgos que pudieran encuadrarse dentro del Magdaleniense (medio o superior) en sentido amplio, sin una mayor precisión.

\section{2. La Escalera 1}

Situado en el T. M. de Arcos de la Frontera, sobre un nivel de arcillas rojas con características hidromorfas (Figura 1, Tabla 1). Fue localizado, al ponerse al descubierto por explotaciones industriales de áridos, con un área de unos $500 \mathrm{~m}^{2}$ de dispersión de materiales y algunas pequeñas concentraciones. Fue descubierto y presentado su material durante el transcurso del Proyecto Guadalete (Giles et al., 1992; Gutiérrez et al., 1994) realizándose años después una intervención arqueológica en la zona con motivo de la ampliación de la explotación de áridos (Cantillo et al., 2014).

Las explotaciones y configuraciones líticas están realizadas sobre sílex en su mayoría, aunque se observaron diversas litologías en el área en el momento de su prospección, como areniscas masivas de grano grueso y fino, sílex con caliza y areniscas fosilíferas. 


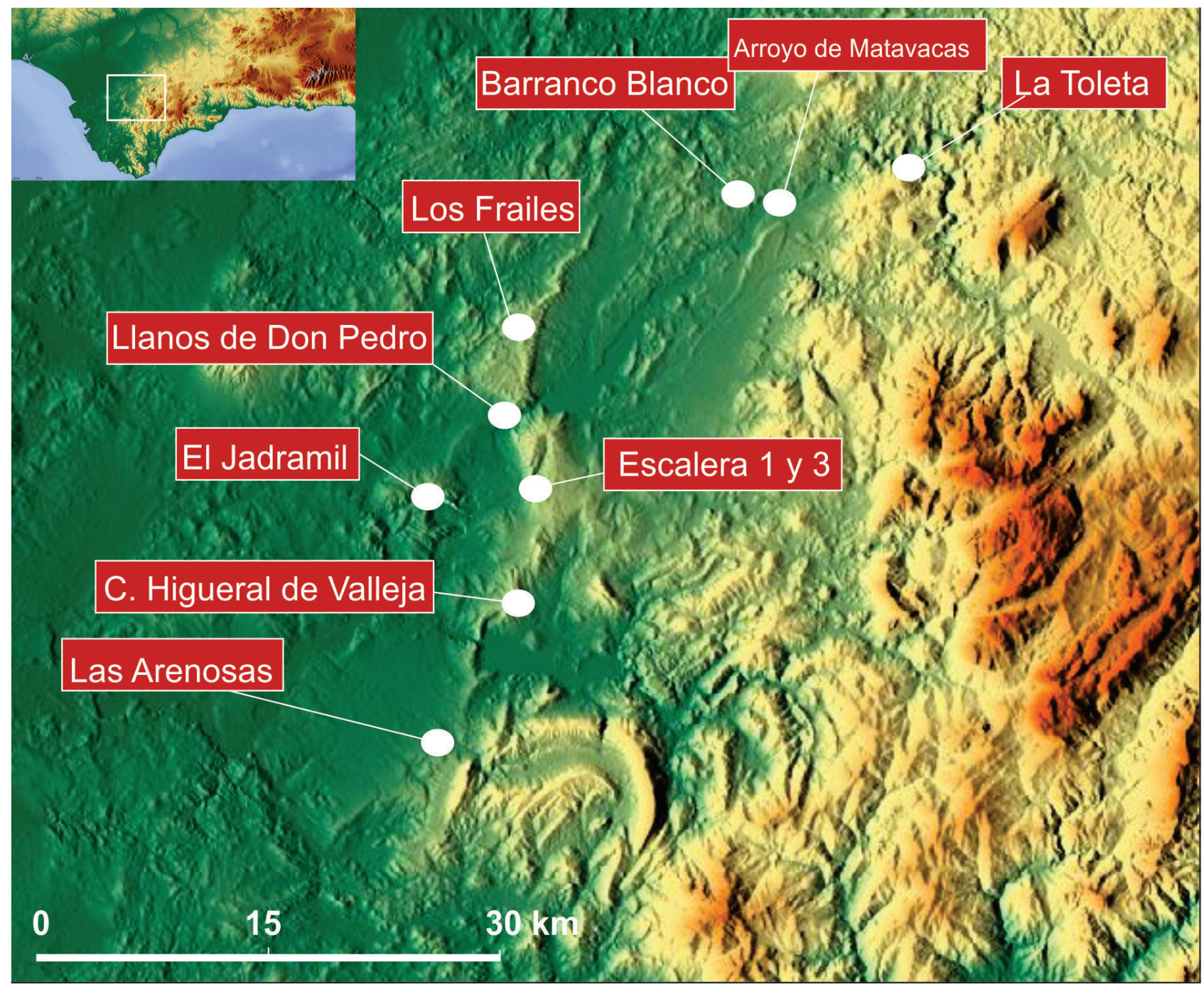

Figura 1. Localizaciones de los yacimientos del Paleolítico superior de la cuenca del Guadalete.

El conjunto lítico detectado durante las primeras prospecciones, está compuesto por núcleos de talla unipolar longitudinal de morfologías prismáticas. En ciertas ocasiones estas bases son reutilizadas con estrategias centrípetas a partir de un traslado de su plataforma. Las lascas, bien representadas, no presentan rasgos diagnósticos, con un porcentaje significativo de lascas semicorticales. Se documentaron cinco raspadores (Figura 3, 19), cuatro buriles sobre truncadura (Figura 3, 20-23), una laminilla con borde abatido, una muesca, un denticulado, cuatro truncaduras y un geométrico (trapecio con dos lados cóncavos), más un ápice triédrico (Figura 3,24 ) y ocho lascas y láminas con retoques más o menos continuos (Giles et al., 1997).

La intervención realizada en fechas posteriores desgraciadamente no pudo aportar más precisiones a la hora del encuadre crono-cultural, deter- minando un predominio de la talla bifacial con influjos de talla levallois, asociados a elementos tecno-tipológicos propios del Paleolítico superior de manera general.

Los autores apuntan a la presencia en superficie de un taller que adscriben en sentido amplio a la Prehistoria reciente aunque con elementos que les sugieren una cronología entre el IV y III milenio a.n.e. (Cantillo et al., 2014). La presencia de un geométrico en los primeros estudios puede apuntar a la continuidad de la ocupación en momentos más tempranos del Epipaleolítico o del Neolítico.

\subsection{La Escalera 3}

El conjunto detectado (Giles et al., 1997) se halló en conexión dentro de un estrato de arenas rojas rubefactadas en el que, al igual que en la lo- 


\begin{tabular}{|c|c|c|c|c|c|c|}
\hline YACIMIENTOS & GRAVETIENSE & $\begin{array}{l}\text { SOLUTRENSE } \\
\text { MEDIO/SUP. }\end{array}$ & $\begin{array}{l}\text { SOLUTRENSE } \\
\text { SUPERIOR }\end{array}$ & MAGDALENIENSE & $\begin{array}{c}\text { PS } \\
\text { INDETERMINADO }\end{array}$ & EPIPALEOLÍTICO \\
\hline Las Arenosas & & & & $\mathrm{x}$ & & \\
\hline Escalera 1 & & & & $\mathrm{x}$ & & $\mathrm{x}$ \\
\hline Escalera 3 & & $\mathrm{x}$ & & & & \\
\hline Llanos de Don Pedro & & $\mathrm{x}$ & & & & \\
\hline El Jadramil & & & & & $\mathrm{x}$ & \\
\hline Los Frailes & & & & $\mathrm{x}$ & & $\mathrm{x}$ \\
\hline Barranco Blanco & & & & & $\mathrm{x}$ & \\
\hline Arroyo de Matavacas & & & & & $\mathrm{x}$ & \\
\hline La Toleta & & & $\mathrm{x}$ & & & \\
\hline Higueral de Valleja & & & $\mathrm{x}$ & & & \\
\hline Higueral La Guardia & & & $\mathrm{x}$ & & & \\
\hline Cueva de la Motilla (AR) & & & $\mathrm{x}$ & & & \\
\hline Cueva de los Márquez (AR) & & & $\mathrm{x}$ & & & \\
\hline VR 15 (AR) & & & $\mathrm{x}$ & & & \\
\hline
\end{tabular}

Tabla 1. Localizaciones del Paleolítico superior de la cuenca del Guadalete y área próxima.

calización anterior, se observa la presencia de una variada gama de litologías: areniscas, calizas y algunas cuarcitas, estando la industria lítica realizada exclusivamente sobre sílex. Este yacimiento se encuentra localizado también dentro del T. M. de Arcos de la Frontera (Figura 1, Tabla 1).

Los núcleos presentan una estrategia de talla longitudinal, en algunos casos bipolar, buscando la producción de elementos laminares, encontrándose en diferentes estadios de la producción, desde el inicio de su talla hasta la reducción total del núcleo. En el estudio de los productos de lascado se observa la presencia de elementos con córtex, en un porcentaje similar a los productos más tardíos dentro del proceso de talla. Este hecho junto a la aparición de núcleos en diferentes fases de la producción así como de elementos finales ya retocados, podría indicar un desarrollo total de las cadenas operativas dentro de esta localización (Gutiérrez et al., 1994).

$\mathrm{Al}$ igual que sucede en el anterior yacimiento, es escaso el conjunto de materiales retocados, aunque con algún elemento que puede ayudarnos a su determinación tecno-cultural. Los modos de retoques más comunes son el simple y el abrupto, confeccionándose un conjunto de útiles formado por: dos raspadores (Figura 4, 2 y 3), un buril (Figura 4,4), tres láminas con borde abatido, una muesca (Figura 4,11), tres denticulados (Figura 4,9 y 10) y 17 productos entre lascas y láminas con retoque abrupto (Figura 4, 5-8). La presencia de un foliáceo con retoque subparalelo plano y cubriente (Figura 4,1 ), descrito como un fragmento basal de hoja de laurel puede encuadrar este yacimiento dentro del Solutrense.

\subsection{Llanos de Don Pedro}

Yacimiento localizado en el contacto entre un glacis de areniscas y arenas con una terraza del río Guadalete, de edad Pleistoceno medio-superior (Figura 1, Tabla 1), situado en el T. M. de Arcos de la Frontera. Dentro de este contexto y, nuevamente, sobre niveles de arenas rojas, se documentó un conjunto lítico que permitió un encuadre dentro del Solutrense de manera general. El conjunto está conformado por un núcleo prismático multipolar dirigido a la obtención de productos laminares (Figura 5,3 ) y algunos útiles retocados como buriles sobre truncadura (Figura 5, 2 y 4), láminas retocadas y finalmente un fragmento basal de foliáceo con retoque plano (Figura 5, 1), que permite, al igual que en La Escalera su atribución al Solutrense (Giles et al., 1995).

\subsection{El Jadramil}

Un pequeño conjunto de raspadores y buriles fue detectado en esta localización de Arcos de la Frontera (Figura 1, Tabla 1), insertos en un depósito de glacis de arenas rojas, a techo del sustrato geológico de calcarenitas, durante trabajos de seguimiento arqueológico de una explotación de áridos (Giles et al., 1998). Las características de los útiles los enmarcan dentro del Paleolítico superior pero sin poder precisar más (Figura 5, 5-13).

\subsection{Los Frailes}

Situado en la vertiente occidental de la sierra del Calvario sobre un glacis de arenas rojas entre 


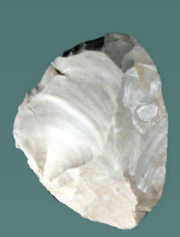

1

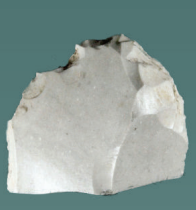

2

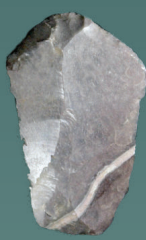

3

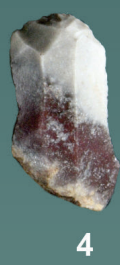

4

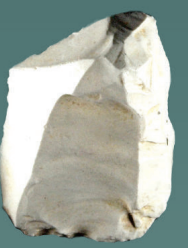

5

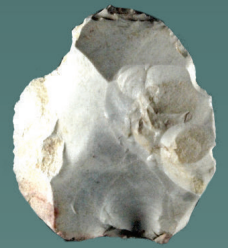

6

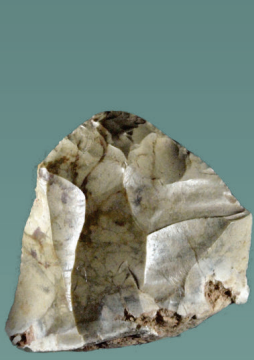

7
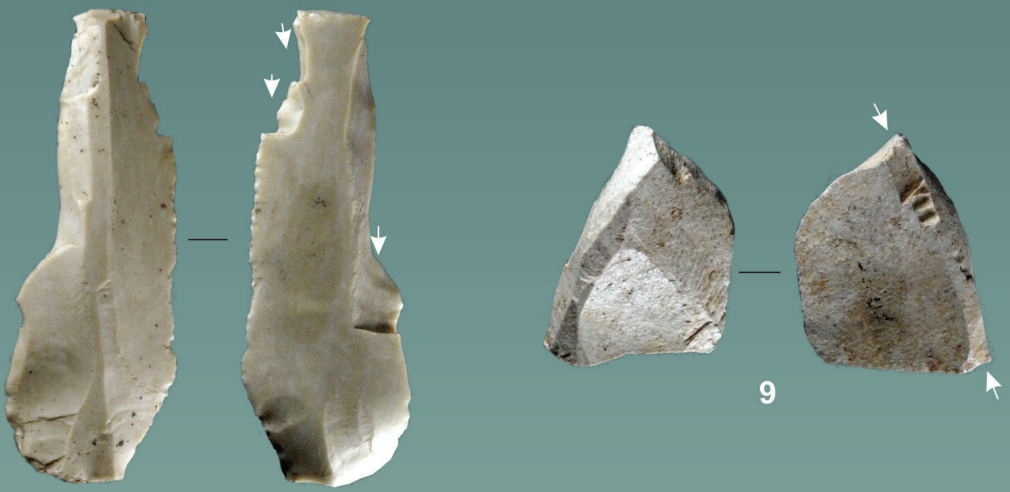

8
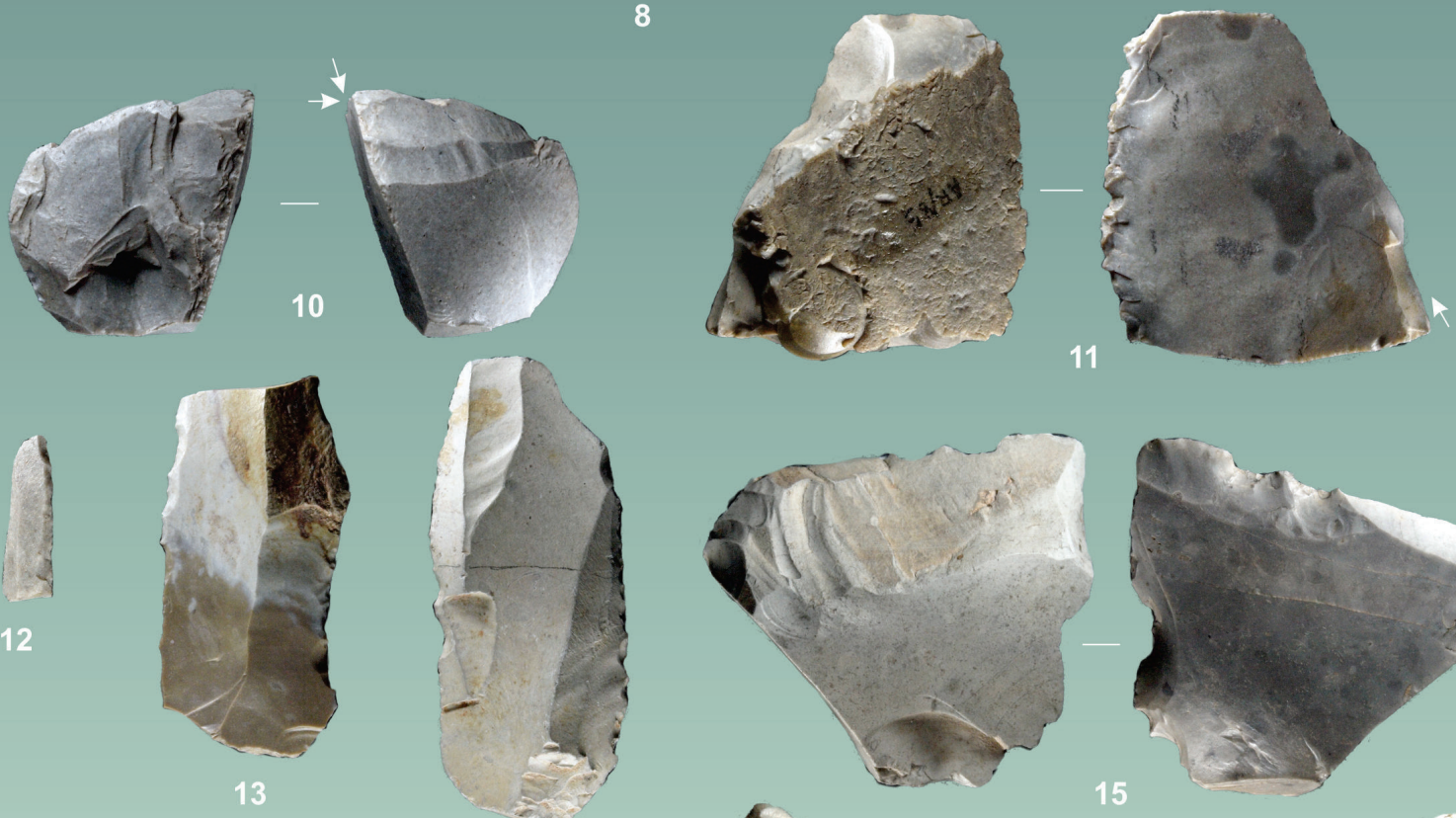

14
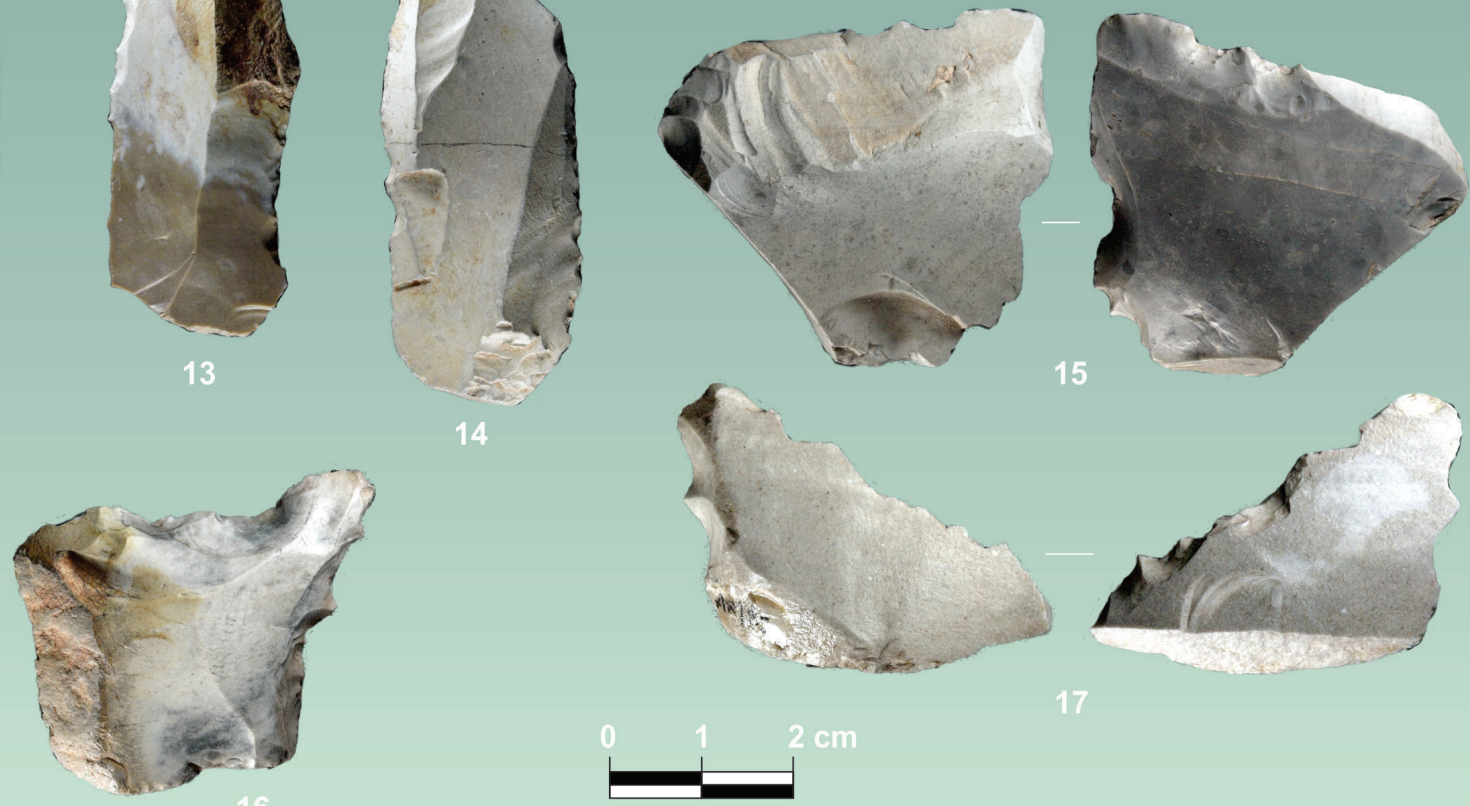

16

Figura 2. Las Arenosas (Arcos de la Frontera): 1-7: Raspadores; 8-11: Buriles; 12-14: Laminita y láminas con borde abatido; 15-17: Muescas y denticulados.

Revista Atlántica-Mediterránea de Prehistoria y Arqueología Social 22, pp. 43-78 


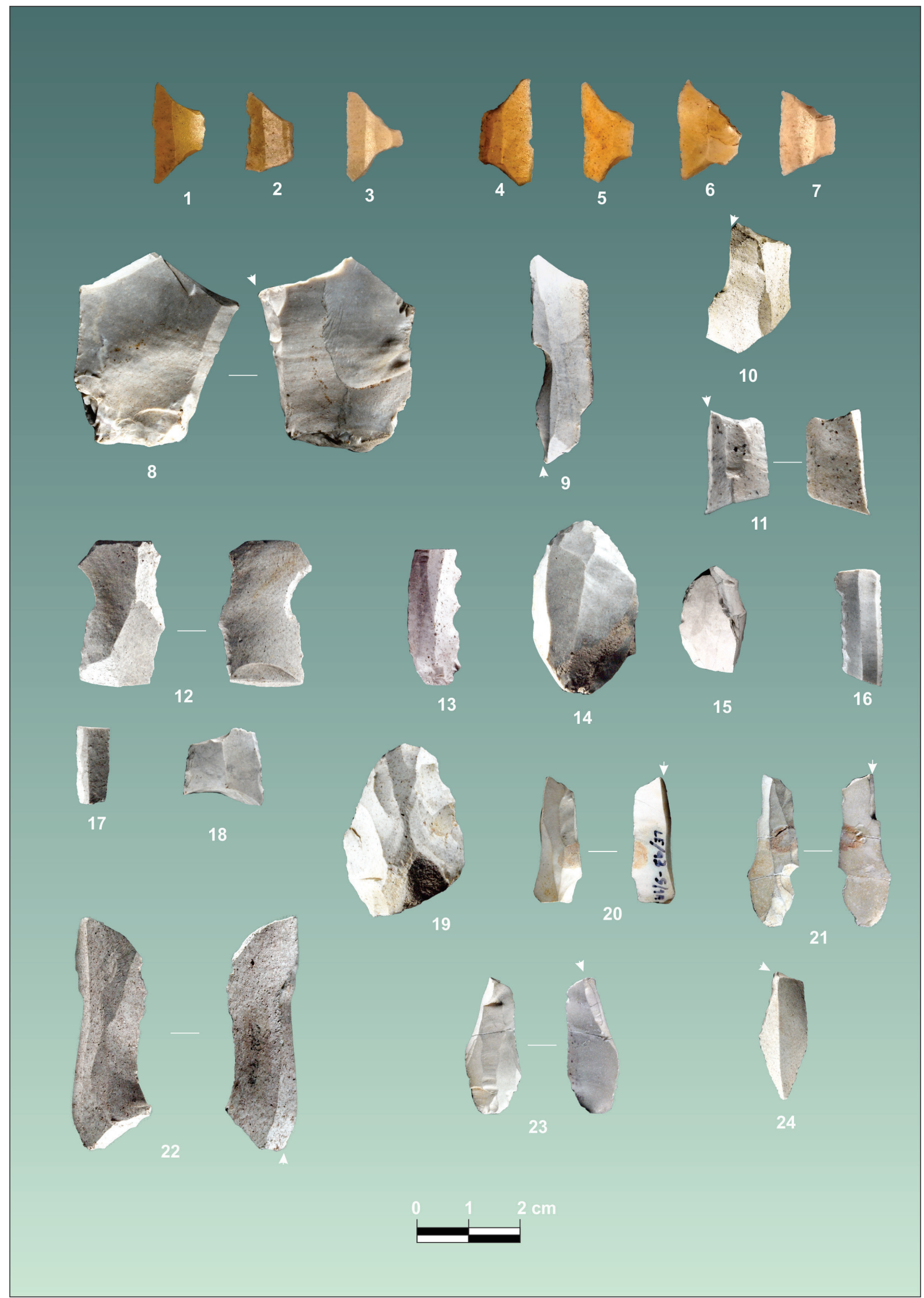

Figura 3. Los Frailes (Bornos/Espera): 1-7: Geométricos; 8-11: Buriles; 12: Muesca; 13: Denticulado sierra; 14 y 15: Raspadores; 16-18: Láminas de bordes abatidos. Escalera 1 (Arcos de la Frontera): 19: Raspador; 20-23: Buriles; 24: Ápice triédrico. 
el T. M. de Bornos y el de Espera (Figura 1, Tabla 1). Se trata de un amplio yacimiento en su dispersión de materiales en superficie, con un área de unos $500 \mathrm{~m}^{2} \mathrm{y}$ un alto volumen de hallazgos (Giles et al., 1997).

Los núcleos documentados son escasos en relación a otras categorías estructurales, destacando las estrategias de obtención microlaminar tanto en núcleos como en sus producciones, siendo la materia prima dominante el sílex casi en su totalidad.

El material retocado apunta hacia momentos del Paleolítico superior final, Magdaleniense superior o Epipaleolítico, dada la presencia de geométricos con trapecios (Figura 3,1-7) y microburiles, junto con un amplio conjunto de buriles sobre truncadura, simples y diedros (Figura 3, 8-11) que sobrepasan en índice a los raspadores (Figura 3, 14 y 15). Otro gran conjunto está dominado por lascas y láminas con retoques profundos en forma de muescas, denticulaciones y sierras (Figura 3, 12 y 13), completándose el utillaje con otro grupo de láminas y laminillas de borde abatido (Figura 3, 16-18).

\subsection{Barranco Blanco}

Situado en el T. M. de Villamartín (Figura 1, Tabla 1), sobre un terraza fluvial de la margen derecha del río Guadalete, dentro de un contexto erosivo de suelos pardos y depósitos aluviales de barra (Giles et al., 1997). Se trata de un conjunto a día de hoy indeterminado en su filiación crono-cultural, compuesto por raspadores simples y dobles sobre láminas y lascas (Figura 6, 1-9), junto con buriles simples de uno o dos paños, múltiples y sobre truncadura (Figura 6, 11-14).

\subsection{Arroyo de Matavacas}

Localización de la margen izquierda del Guadalete durante el corto recorrido del río por la provincia de Sevilla, concretamente en el T. M. de El Coronil. El yacimiento se ubica en una cobertera de terraza sobre el nivel T-3 (+ 20-35 m, sobre el talweg actual) de la secuencia general establecida para toda la cuenca (Giles et al., 2003). Es el nivel de terraza que ha conservado mayor desarrollo y sobre él se han formado suelos pardo-rojizos y depósitos finos de arenas. Estos contienen una industria elaborada exclusivamente sobre diferentes variedades de sílex que posee caracteres leptolíticos y rasgos tipológicos atribuibles a un Paleolíti- co superior indeterminado (Figura 6, 11, 15 y 16), sin que existan aquí indicios para una evaluación más precisa (Giles et al., 1999).

\subsection{La Toleta}

El yacimiento arqueológico de La Toleta está situado en el T. M. de Puerto Serrano (Figura 1, Tabla 1), en el límite noreste de la provincia de Cádiz, a 300 m s.n.m. y a unas decenas de metros de la ribera izquierda del río Guadalete en su curso alto. El yacimiento se encuentra cubierto por un depósito de ladera relicto, conformado por materiales detríticos y arcillosos deslizados hacia la plataforma aluvial del río (Giles et al., 2017).

La materia prima fundamental es un sílex masivo de excelente calidad para la talla, con variabilidad de tonalidades y una presencia mínima de areniscas compactas de grano fino del Flysch del Aljibe.

Se observa un amplio conjunto de productos de lascas y láminas, siendo los porcentajes muy equilibrados y coincidentes con las estrategias de reducción y los negativos de los núcleos contabilizados. Los núcleos aparecen en diversas fases de producción desde las preformas hasta los ya agotados o fracturados. Los ejemplos con estrategia centrípeta, unifaciales y bifaciales, suelen ser los más numerosos. Tampoco faltan los procesos de talla que generan volumetrías prismáticas y poliédricas. Los núcleos para producción laminar se caracterizan por ser de tipo prismático, de talla unipolar especialmente, estando también representados con formato piramidal de los que se extrajeron productos microlaminares. El utillaje más abundante está compuesto por las piezas con retoques simples continuos y discontinuos sobre lascas ordinarias y de módulo laminar. El grupo integrado por los tipos de muescas simples y piezas con escotadura es otro de los más característicos (Figura 7, 14-16). Los denticulados y las raederas quedan en proporciones más reducidas respecto al resto de los productos configurados por retoques. La relación entre raspadores y buriles es equilibrada, con raspadores frontales planos y frontales espesos, configurados sobre lascas y láminas internas (Figura 7, 10-13). Los buriles están más diversificados en cuanto a su configuración final, con presencia de buriles simples sobre fractura, sobre truncadura, diedros y nucleiformes (Figura 7, 5-9). Los retoques planos cubrientes están representados por utillaje del grupo solutren- 


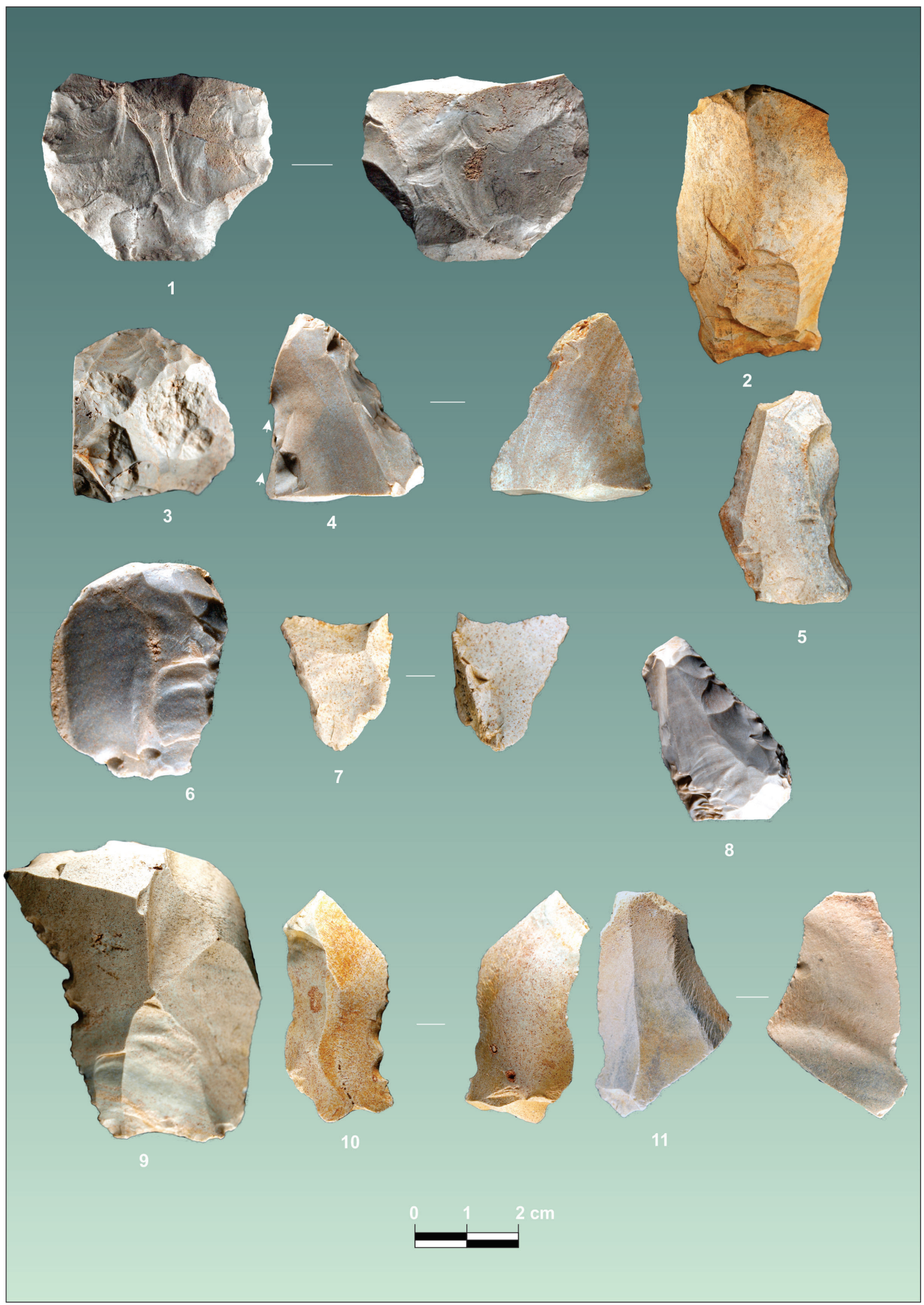

Figura 4. Escalera 3 (Arcos de la Frontera): 1: Foliáceo; 2 y 3: Raspadores; 4: Buril; 5-8: Retoques abruptos; 9 y 10: Denticulados; 11: Muesca. 


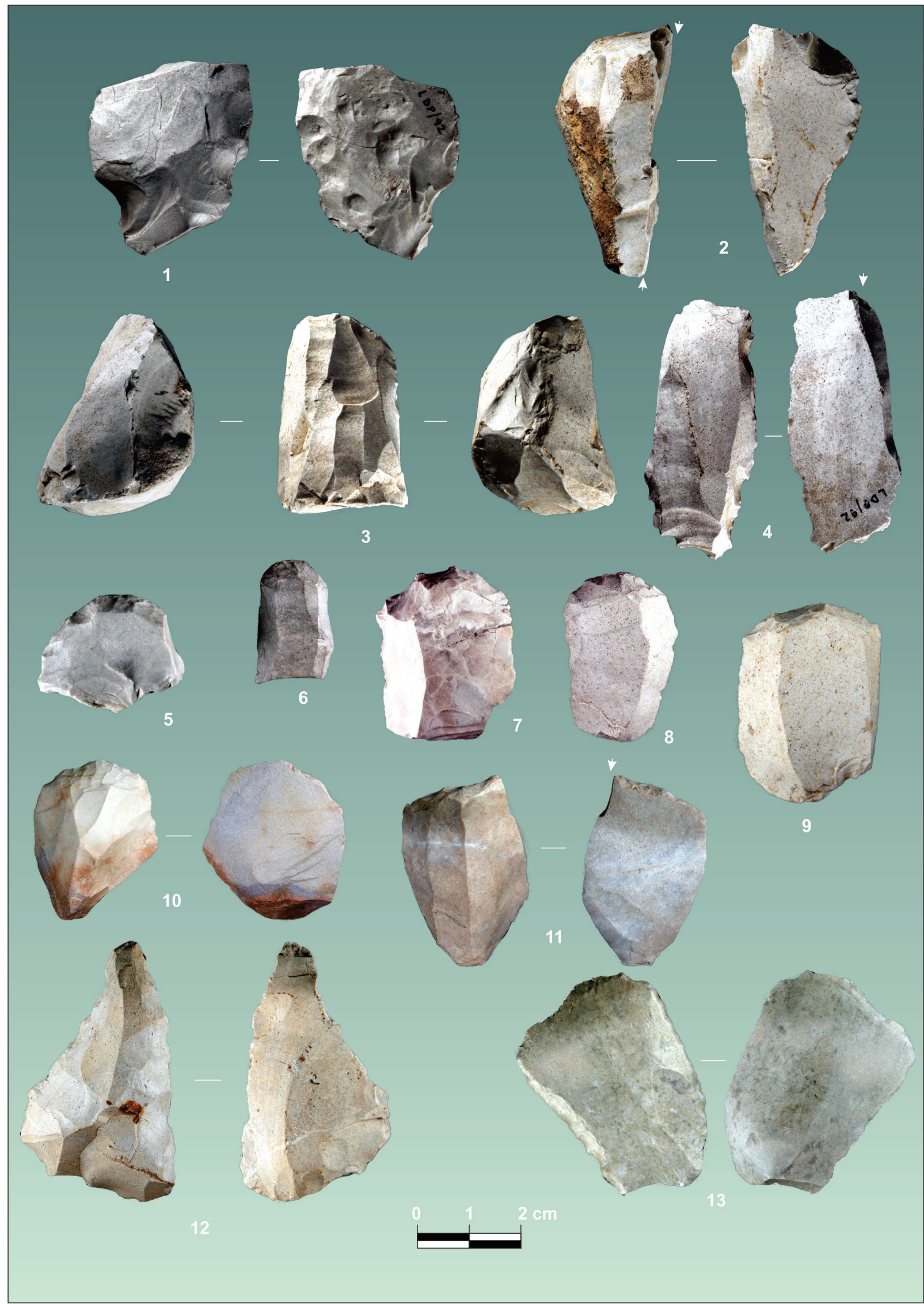

Figura 5. Llanos de Don Pedro (Arcos de la Frontera): 1: Foliáceo; 2 y 4: Buriles; 3: Núcleo; 4; Jadramil (Arcos de la Frontera): 5-10: Raspadores; 11: Buril; 12: Denticulado; 13: lasca con bordes abatidos.

Revista Atlántica-Mediterránea de Prehistoria y Arqueología Social 22, pp. 43-78 


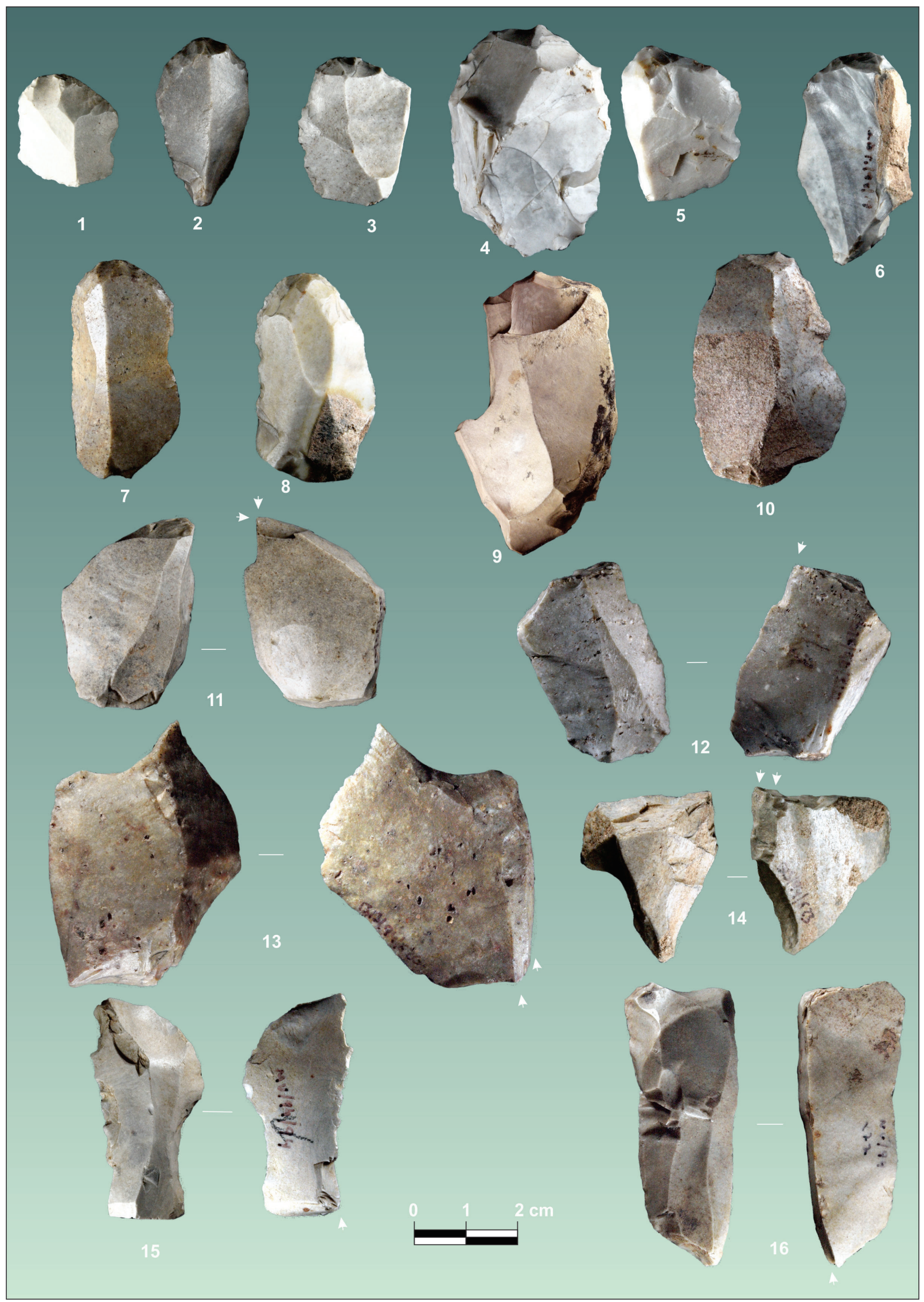

Figura 6. Barranco Blanco (Villamartín): 1-9: Raspadores; 11-14: Buriles.

Arroyo de Matavacas (El Coronil): 10: Raspador; 15: Buril; 16: Raspador-Buril sobre truncadura.

Revista Atlántica-Mediterránea de Prehistoria y Arqueología Social 22, pp. 43-78

Universidad de Cádiz 


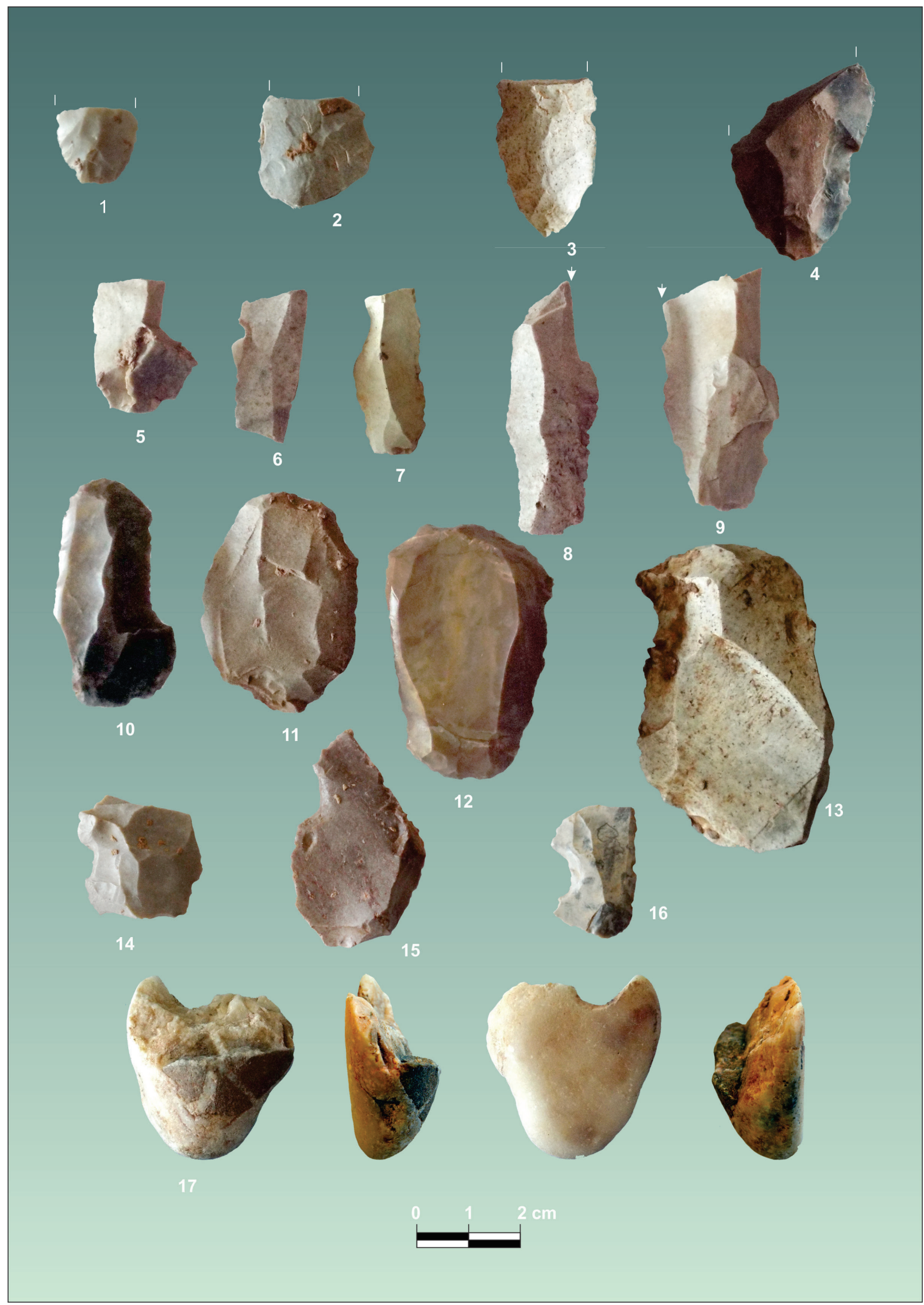

Figura 7. La Toleta (Puerto Serano): 1-4: Foliáceos; 5-7: retoques abruptos; 8-9: Buriles; 10-13 Raspadores; 14-16: Muescas; 17: Canto perforado, colgante.

Revista Atlántica-Mediterránea de Prehistoria y Arqueología Social 22, pp. 43-78 
se. Las piezas identificadas corresponden a foliáceos apuntados bifaciales del tipo hoja de laurel y unifaciales de base convexa, junto a una preforma de armadura bifacial (Figura 7,1-4), lo que apunta hacia una adscripción de este yacimiento al Solutrense.

Mención aparte merece la documentación en este yacimiento de un colgante elaborado en calcita caracterizado por haberse configurado sobre un pequeño canto ligeramente traslúcido, de perfil cónico, con unas dimensiones mayores en lo conservado de $35 \mathrm{~mm}$ de longitud, 33 de anchura y 18 de espesor. Se trata de un canto rodado de caliza micro-cristalina, de grano medio y color pardo grisáceo claro, que presenta fracturación y relleno de la misma con venas de calcita esparítica recristalizada, con posible origen local (Giles et al., 2016).

\section{Yacimientos en Cueva}

\subsection{Cueva de Higueral de Valleja}

En este mismo marco regional existen testigos del Subbético interno, como la Sierra de Valleja en Arcos de la Frontera (Figura 1, Tabla 1), donde se localiza la Cueva del Higueral, dominando un amplio territorio por el que discurre el tramo bajo del río Majaceite hasta su unión con su colector principal, el río Guadalete. Además del propio interés biogeográfico que tiene la cavidad por su posición, se trata de la única estación paleolítica en este territorio que ha sido investigada mediante excavación arqueológica, mostrando una amplia secuencia estratigráfica que abarca tanto Paleolítico superior como medio. También es el único enclave, dentro de este marco, con dataciones absolutas (Jennings et al., 2009), estudios paleoecológicos, tafonómicos (Cáceres, 2003) y con análisis detallados desde una perspectiva tecnológica y funcional del conjunto atribuido al Paleolítico superior (Giles-Guzmán et al., 2017).

Los niveles adscritos al Paleolítico superior dentro de la secuencia estratigráfica de la cavidad son los denominados III y IV, siendo el primero determinado como Solutrense superior ibérico y el segundo dada la escasez de elementos diagnósticos y problemáticas en cuanto a la seguridad de las dataciones como Paleolítico superior indeterminado, aunque en algún momento se llegó a apuntar su posible atribución Gravetiense (Giles et al., 2012; Jennings et al., 2009). A día de hoy esta atribución es arriesgada a partir del estudio tec- nológico, cuestión que ya se puso de manifiesto en un trabajo anterior (Giles-Guzmán et al., 2017), al cual remitimos para una visión más completa del estudio tecnológico y funcional.

Se han realizado varios análisis desde diferentes disciplinas para la comprensión del paleoambiente reflejado dentro de esta secuencia (Jennings et al., 2019), aunque centrándose en los niveles del Paleolítico medio. Se observa la aparición de carbones de difícil identificación, aunque se pudo precisar la presencia de Pinus nigra o pino de montaña, asociado con temperaturas más frías a las actuales en el área de la cavidad. Los estudios de micromamíferos muestran un paisaje con espacios abiertos salpicados de áreas boscosas con la presencia de Crocidura russula en los niveles II y IV. De ambiente rupícola y boscoso es el taxón Eliomys quercinus y asociado a matorrales y bosques se documentó la especie Microtus brecciensis. Otras especies como Apodemus sylvaticus o Oryctolagus cuniculus entran bien dentro de este rango. Entre los macromamíferos contamos con la presencia mayoritaria de Cervus elaphus junto con algunos restos de Equus sp. y Bos/Bison sp. en ambos niveles, documentándose un carnívoro como Canis lupus en el nivel III.

El nivel III está caracterizado por 31 objetos que reúnen los caracteres morfotécnicos, como el uso del retoque para su inclusión en la categoría estructural de útiles, así como de elementos laminares (Figura 8, 10-14). Se han documentado siete ejemplares de raederas con las siguientes características: una con retoques simples marginales continuos, una con retoques simples latero-transversales, una raedera doble lateral con retoques profundos, tres raederas laterales con retoques simples, una de ellas sobre la cara ventral y una raedera denticulada. Los denticulados son seis en total, cinco denticulados laterales con retoques profundos, dos de ellos realizados sobre sílex y radiolarita que se encuentran termo-alterados, y un denticulado lateral con retoques simples. Los buriles cuentan con cuatro ejemplares (Figura 8, 8 y 9), un buril lateral con retoques marginales, un buril lateral carenado con retoque de paro plano directo, un buril distal y un buril triangular con picante triedro profundo. Raspadores contabilizamos cuatro (Figura 8, 5-7): un raspador frontal simple carenado profundo, un raspador lateral derecho, un raspador semicircular marginal y un raspador inverso. De truncaduras sólo se ha documentado un ejemplar y de carácter marginal. Las 


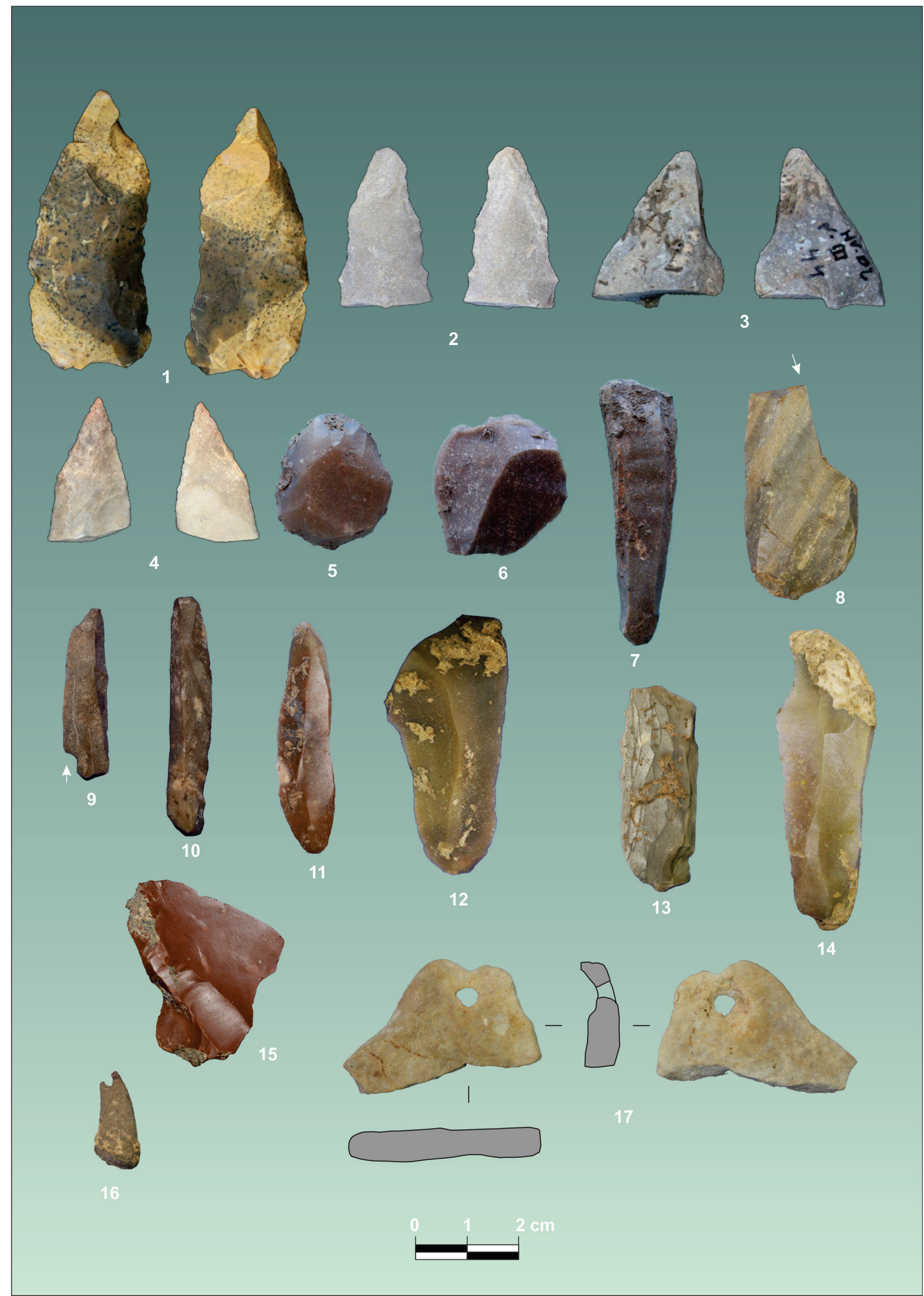

Figura 8. Higueral de Valleja (Arcos de la Frontera): 1-4 Foliáceos; 5-7: Raspadores; 8 y 9: Buriles; 10-14: Láminas con retoques abruptos; 15: Muesca; 16: Diente de ciervo perforado, colgante; 17: Plaqueta de caliza perforada, colgante.

Revista Atlántica-Mediterránea de Prehistoria y Arqueología Social 22, pp. 43-78 
puntas se elevan a seis ejemplares, dos fragmentos mediales de puntas bifaciales de retoque plano, una punta foliácea de aletas y pedúnculo, dos fragmentos distales de puntas foliáceas bifaciales y un pedúnculo de punta foliácea profunda (Figura 8,1-4). Terminándose este repertorio con la documentación de una lasca con retoques simples marginales. Este conjunto dada la presencia de puntas de aletas y pedúnculo, hojas de laurel con extremo ojival y su posición estratigráfica respecto a las dataciones directas, se determina con claridad como Solutrense superior ibérico (Fullola et al., 2005).

En el nivel IV se han documentado diecisiete lascas retocadas lo que supone casi un tercio del material conseguido a través de estrategias de explotación. Entre los útiles del nivel IV se han contabilizado los siguientes morfotipos: dos buriles simples, dos denticulados, uno marginal y otro lateral, cinco piezas con muescas marginales, dos raspadores circulares, una punta de dorso parcial secante y finalmente un fragmento de lámina con retoque de dorso.

En anteriores trabajos, planteamos la posibilidad de una atribución Gravetiense para el nivel IV, dada la documentación de retoques abruptos en una punta de dorso y la ausencia de retoques planos. Tras una visión más detenida del conjunto, pensamos que es aun arriesgada la adscripción del Nivel IV a un tecno-complejo del Paleolítico superior concreto, más allá de su correlación estratigráfica, máxime con unas dataciones disponibles no concordantes con este encuadre. Tras los análisis de las diferentes características tecnológicas de ambos conjuntos, siendo el nivel IV aun escaso, observamos una importante convergencia en las estrategias de talla en varios estadios de transformación, por lo que no es descartable su posible atribución a fases anteriores del Solutrense, teniendo en cuenta el escaso volumen excavado, que obviamente determina la escasez de piezas diagnósticas (Giles-Guzmán et al., 2017).

Dentro del registro arqueológico de la Cueva del Higueral destacan dos elementos ornamentales: un colgante configurado sobre una plaqueta de caliza (Figura 8, 17) y un canino deciduo de ciervo perforado (Figura 8, 16), ambas piezas con presencia de impregnaciones de ocre rojo. Del colgante configurado sobre plaqueta se conserva su parte proximal, donde se sitúa la perforación. Por el aspecto de las ranuras y sus trazas abruptas, la perforación debió realizarse desde una de sus caras por percusión indirecta (Soler, 2001), median- te un instrumento duro, quizás una punta o perforador lítico. Los estigmas conservados presentan un tipo característico de hendiduras, que fueron ampliándose en extensión conforme progresaba la perforación.

\section{El contexto regional del sur de la península Ibérica}

\subsection{Paleolítico superior inicial: Auriñaciense y Gravetiense}

El estudio de los inicios del poblamiento del Hombre Anatómicamente Moderno (en adelante HAM) durante el comienzo del Paleolítico superior, centra su interés en esta zona en relación a la posible pervivencia, en áreas refugio mediterráneas, de las poblaciones neandertales (Finlayson et al., 2006; Jennings et al., 2011). Esto es debido, principalmente, a sus particulares condiciones ecológicas, no expuesta a las alteraciones que caracterizan el MIS 3 (Carrión et al., 2018). Otras propuestas de persistencia de estas poblaciones neandertales se sustentan en diferencias bio-geográficas a un lado y otro del Ebro (Zilhão, 2000), hasta momentos coincidentes con el Auriñaciense evolucionado (Zilhão, 2006; Zilhão et al., 2015). Esta perduración de poblaciones neandertales se soporta en varias series de dataciones de conjuntos musterienses realizadas en cavidades de Gibraltar, en el suroeste (Finlayson et al., 2008; Giles et al., 2012) y Murcia, en el sudeste (Zilhão et al., 2017). Este fenómeno de perduración es también planteado, pero aún por confirmarse, debido a la falta de correlación con conjuntos técnicos Musteriense bien definidos, en la Cueva de la Carihuela (Carrión et al, 2019), siendo necesaria una reactivación más amplia de sus estudios para abordar esta cuestión, máxime si tenemos en cuenta que se trata de la cavidad con la que comenzaron a realizarse este tipo de propuestas (Vega, 1990).

Como expondremos a continuación, la ocupación del sur de Iberia por el HAM (Figura 9, tabla 2), se presenta como un fenómeno retardatario respecto a otras zonas de la península Ibérica, tales como la costa levantina o la cornisa cantábrica. No será hasta el Gravetiense cuando encontremos una ocupación, aunque aún todavía restringida, sí ya con un número significativo de yacimientos, cuestión ésta ya planteada anteriormente por otros autores (de la Peña, 2013). A día de hoy, para el periodo Auriñaciense, las ocupaciones claras y 
sin género de dudas sólo las podremos observar en la región de Murcia, prácticamente insertas en la zona levantina y con sólo dos localizaciones adscritas al Auriñaciense evolucionado (Zilhão et al., 2017).

Existen varios conjuntos que han sido descritos como auriñacienses, aunque la mayoría tienen un carácter poco diagnóstico, escaso número de restos o incluso estos son provenientes de contextos claramente alterados. En Zafarraya se ha sugerido la presencia de ocupación Protoauriñaciense, a partir de un pequeño conjunto de láminas retocadas y de bordes rectos que se definen como de tipo Dufour, dentro del denominado complejo estratigráfico superior (A). Este es un depósito de revuelto, con materiales arqueológicos desde el Neolítico final, Calcolítico al Paleolítico superior, donde los autores han diagnosticado la presencia de Solutrense, Gravetiense y Protoauriñaciense (Barroso y Lumley, 2006).

Otro caso lo encontramos en Gorham's Cave en Gibraltar, donde pese a que desde las primeras excavaciones (Waechter, 1951) la adscripción de sus industrias a un Paleolítico superior temprano era más que dudosa. El propio autor (Waechter, 1964) veía similitudes con yacimientos como Parpalló u Hoyo de la Mina, ambos de cronologías más tardías. Posteriores trabajos (Pettit y Bailey, 2000) han insistido en corroborar esta secuencia, pero sin una correlación clara con los conjuntos líticos ni con los niveles descritos por Waechter.

Los últimos estudios realizados sobre la parte alta de la secuencia de la cueva de Gorham, en el área afectada por las excavaciones de Waechter, arrojan más dudas que luz a este respecto, dada la exigua extensión de las zonas excavadas y el carácter poco diagnóstico de los conjuntos recuperados (Barton y Jennings, 2013). Los niveles adscritos al Paleolítico superior, tras un periodo de tres años de excavación, son los denominados $\mathrm{CHm} 3$ a $\mathrm{CHm} 5$. El primero de ellos, en el que sólo se han documentado 27 piezas líticas, está compuesto por un conjunto dominado por lascas, donde la presencia de una pieza astillada con levantamientos para la obtención de laminillas puede tener, según los autores, paralelos en conjuntos gravetienses del Mediterráneo. Si bien un alto índice de astillados es característico de algunos conjuntos, es un indicio bastante pobre para sustentar tal asignación. Del nivel CHm4 sólo fue recuperada una lasca. El conjunto estudiado del Nivel CHm5, presenta una única datación entre 34000-33200 BP. Al igual que el anterior, es escuálido tanto cualitativa como cuantitativamente. Está integrado por un núcleo fragmentado para la obtención de láminas, cuatro láminas carenadas retocadas y una lasca con muesca sin características que puedan asimilarse a la producción de láminas tipo Dufour. El registro se complementa con una concha de caurí perforada con restos de ocre y un fragmento de punta de azagaya de hueso. El estudio de los materiales proveniente de las excavaciones de Waechter de los niveles B, D y F, depositados en el Gibraltar National Museum y estudiados en este mismo trabajo (Barton y Jennings, 2013), plantea una problemática similar al material exhumado en las últimas intervenciones, siendo la única pieza claramente diagnóstica para los autores el extremo proximal de un foliáceo, apuntándose la posibilidad de una mezcla de niveles durante el proceso de excavación, reflejada en algunas discordancias en las colecciones.

Las excavaciones realizadas en la parte interna de Gorham han deparado una estratigrafía con niveles no detectados en la secuencia de Waechter, un nivel Neolítico y dos subniveles superopaleolíticos adscritos al Magdaleniense y al Solutrense, con una serie de dataciones concordantes y bien definido tecnológicamente (Finlayson et al., 2006), con arte rupestre asociado con esta atribución (Balbín et al., 2000; Simón et al., 2009) y datación solutrense (Simón et al., 2018), una punta de azagaya y moluscos perforados. Unos conjuntos que pueden estar en relación con la industria lítica, ósea y ornamental documentada en el área más externa de la cavidad.

En la provincia de Málaga, destaca la Cueva de Bajondillo por una secuencia que abarca desde el Calcolítico hasta fases del Paleolítico medio de finales del MIS 6 (Cortés, 2007). La propuesta de una ocupación Auriñaciense ha sido realizada en varias ocasiones. El nivel BJ/11 fue adscrito, no sin reservas, a este tecnocomplejo (Cortés 2007), tampoco exento de problemáticas, con un conjunto bien definido, aunque escaso, de tecnologías laminares y materiales retocados del Paleolítico superior. En cuanto a su encuadre como Auriñaciense, plantea el problema tanto de su cronología, como de sus rasgos tecno-tipológicos que no lo insertan en un Auriñaciense sensu lato. La secuencia en este tramo presenta una serie conflictiva de dataciones que hacen oscilar este conjunto desde 33690 \pm 1195 por AMS a $26013 \pm 2777$ por TL, siendo para algunos autores un conjunto que habría que 


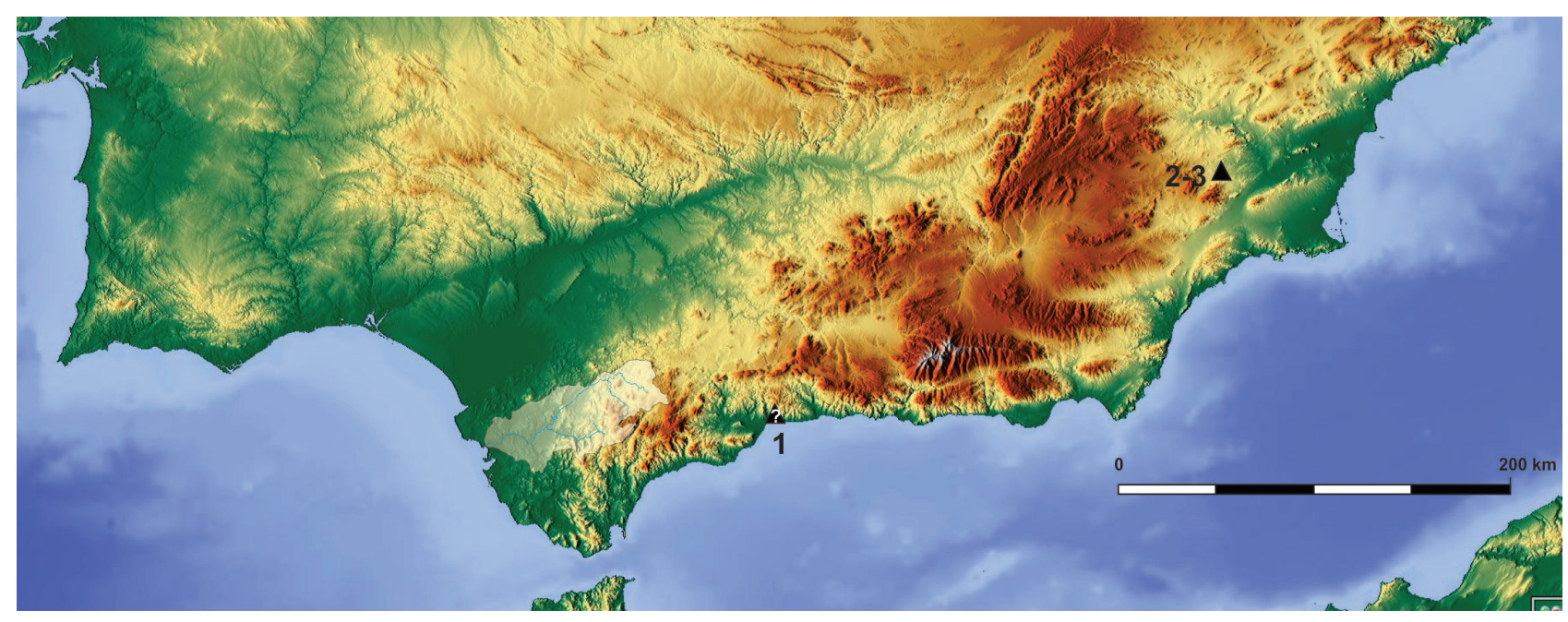

Figura 9. Localizaciones auriñacienses en el sur de Iberia: 1. (?) Bajondillo; 2-3. La Boja, Finca de Doña Martina.

situar en el Gravetiense (de la Peña 2013; Straus, 2018). Recientemente, una serie de dataciones en el nivel infrapuesto a BJ/11, BJ/13 arrojaron fechas por encima de $43 \mathrm{ka}$, que han servido para sugerir a los autores una ocupación muy temprana del sur de la península Ibérica por parte de los HAM (Cortés et al., 2019), proponiendo la presencia de un Proto-auriñaciense o un Auriñaciense temprano. Nuevamente esta asignación no está exenta de conflictos y ha encontrado oposición (Anderson et al., 2019; de la Peña, 2019). Por otro lado, ya se habían barajado problemas de probables contaminaciones con el estrato musteriense anterior debido a procesos de disolución y solifluxión (Cortés, 2007), algo ya apuntado para parte del conjunto industrial (Cortés, 2007). Esta misma problemática puede afectar a las nuevas fechas AMS/ABA, que vuelven a discrepar de otra datación por TL sobre carbonato de $28532 \pm 5319$ (Cortés, 2007). La asignación cultural del propio conjunto, aun arroja más dudas, observándose rasgos superopaleolíticos en un escaso número de piezas retocadas y algunas hojas y hojitas $(14,4 \%$ de un total de 215 piezas objeto de estudio) que se agrupan juntos con lascas y acondicionamientos levallois y raederas de raigambre musteriense. Según sus propios autores, en trabajos anteriores, estos utillajes podrían venir del contacto con el nivel infrayacente (Cortés, 2007) o incluso ser adscritos a un posible Paleolítico medio terminal (Cortés, 2005).

En la región de Murcia, en la cuenca del río Mula, las excavaciones realizadas en los abrigos de Finca de Doña Martina y La Boja, han documentado sendos niveles asignados al Auriñaciense evo- lucionado (Zilhão et al., 2017), con un inicio de la ocupación datado entre los 36-38 ka. Cal. BP para el caso de La Boja, estratigráficamente situado entre el nivel basal Musteriense y un nivel adscrito al Gravetiense pleno. Se trata de un pequeño conjunto con un 33\% de hojas y hojitas, retocadas y no retocadas, dos núcleos para hojas carenadas, un buril y un raspador ambos sobre núcleo, piezas astilladas, tres hojitas Dufour y una tipo Areiro. En Finca de Doña Martina, el nivel, aun no datado directamente, se encuentra bajo un estrato de clara adscripción Gravetiense, datado en 30-31 Ka. Cal. BP y sobre un estrato que contiene claros rasgos musterienses. Se trata de un pequeño conjunto con raspadores carenados en hocico, hojitas con retoque marginal inverso o alternos del tipo Dufour y núcleos prismáticos para la obtención de hojas y hojitas. Todos elementos que se atribuyen bien a estos momentos del Auriñaciense.

Si bien se constata la presencia de un Auriñaciense evolucionado en estas latitudes, en ambos casos estamos ante ocupaciones de baja intensidad, con ausencia de fuegos, sí documentados en los niveles superiores del abrigo de la Finca de Doña Martina. Hay que destacar el solapamiento de la ocupación auriñaciense de La Boja, 36-38 ka Cal. BP, con las fechas del Musteriense tardío de Cueva Antón de 37-38 ka Cal. BP, siendo sugerente que las ocupaciones del auriñaciense asociado al HAM rompan su continuidad de expansión hacia el suroeste peninsular en este punto en concreto, coincidiendo con una de las ocupaciones tardías de los neandertales.

A este respecto es interesante apuntar, aunque 
fuera de nuestro área de estudio, la secuencia registrada en Lapa do Picareiro (Haws et al., 2020) en el área central de Portugal. Aquí se ha definido un conjunto industrial como Auriñaciense temprano en el nivel GG-II (41-38 ka), sobre un nivel que se adscribe al Paleolítico medio por tecnología, con un conjunto sin levallois y de estrategias discoidales (Nivel JJ, datado en 44-42 ka). Esto supondría el solapamiento en este territorio con las poblaciones neandertales documentadas en Gruta da Oliveira (Angelucci et al., 2009), pudiendo proponerse la posibilidad de una población tipo mosaico, cercana a lo que se desprende de las dataciones de la región de Murcia o propuesto por otros autores para el caso de Bajondillo. No obstante, mantenemos las reservas en este último, aunque no es un escenario que deba ser desechado si partimos de la interpretaciones a pequeña escala de estos refugios biogeográficos en el que quedarían reducidas las ultimas poblaciones neandertales (Jennings et al., 2011).

Como evidencia de un arte relacionado con el Paleolítico superior temprano, con dataciones propuestas de las series de Uranio y AMS sobre diferentes materiales que entrarían dentro de este periodo, se ha sugerido una serie de grabados de la Cueva de las Ventanas en Granada (Cortés et al., 2018). Las dataciones de series de uranio sobre espeleotemas cubriendo los grabados, arrojan una fecha entre 17 ka y $10 \mathrm{ka}$, que una vez calibradas, se cruzan con la serie de dataciones realizadas por radiocarbono, una de las cuales arroja una fecha entre 35.887 - 37997 Cal. BP. Aun así, la propuesta no está exenta de conflicto debido a que una de las muestras datadas fue realizada sobre carbonataciones en un raspador de una colección lítica proveniente de excavaciones antiguas, supuestamente en relación estratigráfica con el arte pero sin ninguna constatación fidedigna. Este conjunto es parco y poco diagnóstico incluso con la posible presencia de una escama de foliáceo que los investigadores descartan del estudio. Otra datación por encima de 30 ka se obtiene de un diente de hiena, que tampoco podemos relacionar estratigráficamente con los grabados o la ocupación humana. Finalmente una única datación de las carbonataciones sobre uno de los trazos que componen el extenso panel gráfico arroja una fecha de 30408 \pm 258 . La poca fiabilidad de las relaciones estratigráficas establecidas, así como los procesos que se infieren de sedimentación, erosión y re-sedimentación sobre los grabados, hacen aventurada una atribución tan antigua. Por otro lado, aun estando el panel compuesto por una serie de líneas incisas sin patrón aparente, en las contadas excepciones que conforman zoomorfos, se observa una concepción trilineal que caracteriza a una gran parte del arte figurativo solutrense del Mediterráneo, siendo posiblemente las dataciones de serie de Uranio las más cercanas a la fecha de realización de los grabados, con una ocupación durante este periodo en la cavidad plenamente constatada (Riquelme et al., 2020).

Durante el Gravetiense comenzamos a ver una clara ocupación en el sur de la península Ibérica (Figura 10, Tabla 2), con varios yacimientos que presentan coherencia entre las dataciones y los conjuntos tecnológicos, en un amplio rango geográfico que abarca tanto la vertiente mediterránea como la atlántica peninsular.

En un recorrido de Este a Oeste se ha documentado la presencia de un Gravetiense antiguo en la cueva murciana de La Boja (Zilhão et al., 2017) donde se observa un aumento de la frecuentación del sitio con respecto al Auriñaciense. No son muchos los elementos diagnósticos respecto al total de la muestra estudiada pero sí clarificadores, con la presencia de un buril tipo Noailles, buriles sobre truncaduras, núcleos-buril, puntas gravetienses y microgravettes. La ocupación de este abrigo presenta una continuidad ocupacional durante el Gravetiense medio, con un conjunto cuantitativa y cualitativamente más amplio y con la presencia de elementos colgantes-ornamentales sobre moluscos marinos perforados. Ambos niveles cuentan con dataciones directas de 30-31 ka cal. BP y 27-31 ka cal. BP respectivamente. Una secuencia similar se observa en el abrigo cercano de Finca de Doña Martina con fechas de $31 \mathrm{ka}$ Cal. BP para el Gravetiense medio y 31 ka Cal. BP para un escaso conjunto de piezas adscritas al Gravetiense antiguo. Dentro del área murciana habría que sumar a la lista de yacimientos con ocupación gravetiense, la Cueva del Arco en Cieza. Aún en proceso de estudio, se señala la presencia de varias estructuras de combustión con fechas del Gravetiense antiguo, 31000-30000 Cal BP (Martín-Lerma et al., 2020).

Estas cronologías entre 31 y 27 ka para la fase inicial del Gravetiense en el sur peninsular, se observan igualmente en el abrigo de El Palomar en Ciudad Real (de la Peña, 2013), donde se han puesto de manifiesto claras afinidades en las estrategias de talla con el área levantina, concretamente con la cavidad de Mallaetes, a través de una secuencia 


\begin{tabular}{|c|c|c|c|c|c|c|c|c|c|}
\hline \multirow{2}{*}{ LOCALIZACIONES } & \multirow{2}{*}{ AURIÑACIENSE } & \multirow{2}{*}{ GRAVETIENSE } & \multicolumn{4}{|c|}{ SOLUTRENSE } & \multicolumn{3}{|c|}{ MAGDALENIENSE } \\
\hline & & & INFERIOR/Protosolutrense & PLENO & SUPERIOR & SOLUTROGRAVETIENSE & INFERIOR & PLENO & SUPERIOR \\
\hline \multicolumn{10}{|c|}{ CADVY } \\
\hline C. del Higueral & & $?$ & & & $\mathrm{x}$ & $\mathrm{x}$ & & & \\
\hline Escalera 3 & & & & & $?$ & & & & \\
\hline Llanos de Don Pedro & & & & & $?$ & & & & \\
\hline Los Frailes & & & & & & & & & $?$ \\
\hline Las Arenosas & & & & & & & & & $?$ \\
\hline La Toleta & & & & & $\mathrm{x}$ & & & & \\
\hline VR-15 (AR) & & & & & $\mathrm{x}$ & & & & \\
\hline Fontanilla & & & & & $\mathrm{x}$ & & & & \\
\hline Casa de Postas & & & & & $\mathrm{x}$ & & & & \\
\hline C. Higueral-la Guardia & & & & & $\mathrm{x}$ & & & & \\
\hline C. de la Motilla (AR) & & & $?$ & $?$ & $?$ & & & & \\
\hline Tajo de las Figuras (AR) & & & $?$ & $?$ & $?$ & & & & \\
\hline Cueva de Levante & & & & & $\mathrm{x}$ & $\mathrm{x}$ & & & \\
\hline C. de los Márquez (AR) & & & $?$ & $?$ & $?$ & & & & \\
\hline C. del Moro (AR) & & & $?$ & $?$ & $?$ & & & & \\
\hline C. de las Palomas (AR) & & $?$ & $?$ & $?$ & $?$ & & & & \\
\hline C. de las Estrellas (AR) & & $?$ & & & & & & & \\
\hline Torre del Almirante & & & & & $x$ & & & & \\
\hline Embarcadero Palmones & & & & & & & & & $\mathrm{x}$ \\
\hline \multicolumn{10}{|c|}{ GIBRALTAR (UK) } \\
\hline Gorham's Cave (I+AR) & & & & & $\mathrm{x}$ & $\mathrm{x}$ & & & $\mathrm{x}$ \\
\hline Sewell's Cave & & & & & $\mathrm{x}$ & $x$ & & & \\
\hline Martin's Cave (AR) & & & & & $\mathrm{x}$ & & & & \\
\hline \multicolumn{10}{|c|}{ MATLAGA } \\
\hline C. de la Pileta (AR) & & $\mathrm{x}$ & & $\mathrm{x}$ & $\mathrm{x}$ & & & $\mathrm{x}$ & $\mathrm{x}$ \\
\hline C. de Ardales (I+AR) & & $?$ & & $\mathrm{x}$ & $\mathrm{x}$ & & & $\mathrm{x}$ & $x$ \\
\hline Bajondillo & $?$ & $\mathrm{x}$ & & $\mathrm{x}$ & & $\mathrm{x}$ & & & \\
\hline Complejo del Humo & & & & $\mathrm{x}$ & $\mathrm{x}$ & $\mathrm{x}$ & & & $\mathrm{x}$ \\
\hline Hoyo de la Mina & & & & & $\mathrm{x}$ & & & & $x$ \\
\hline Higueron & & & $?$ & $?$ & $\mathrm{x}$ & $\mathrm{x}$ & & & $x$ \\
\hline C. Victoria & & & $?$ & $?$ & $?$ & & & & \\
\hline Navarro IV (AR) & & & $?$ & $?$ & $?$ & & & & \\
\hline C. de Zafarraya & & & & & $\mathrm{x}$ & $\mathrm{x}$ & & & \\
\hline El Duende & & & & & & & & & $\mathrm{x}$ \\
\hline C. Tapada & & & & & & & & & $\mathrm{x}$ \\
\hline C. de Nerja (I+AR) & & $\mathrm{x}$ & $\mathrm{x}$ & $\mathrm{x}$ & & $\mathrm{x}$ & & & $\mathrm{x}$ \\
\hline & & & $|A B|$ & & & & & & \\
\hline Peña Grieta & & & & & $\mathrm{x}$ & & & & \\
\hline Cueva del Morrón (AR) & & & $?$ & $?$ & $?$ & & & & \\
\hline & & & $C O R D C$ & $\mathrm{BA}$ & & & & & \\
\hline El Pirulejo & & & & & $\mathrm{x}$ & & & $\mathrm{x}$ & $\mathrm{x}$ \\
\hline & & & SEVII. & & & & & & \\
\hline Los Álamos & & & & & $\mathrm{x}$ & & & & \\
\hline & & & GRANA & DA & & & & & \\
\hline Pantano de Cubillas & & & & & & $x$ & & & \\
\hline Malalmuerzo (I+AR) & & & $?$ & $?$ & $?$ & & & $\mathrm{x}$ & \\
\hline C. de las Ventanas (I+AR & $?$ & $?$ & & & $\mathrm{x}$ & & & & \\
\hline \begin{tabular}{l|l} 
C. de los Ojos \\
\end{tabular} & & & & & $x$ & & & & \\
\hline Tajo de los Marchales & & & & & & & $\mathrm{X}$ & & \\
\hline & & & AMNIB & RiA & & & & & \\
\hline C. Ambrosio (I+AR) & & & & $\mathrm{X}$ & $\mathrm{X}$ & & & & \\
\hline & & & MURC & & & & & & \\
\hline La Boja & $x$ & $\mathrm{x}$ & $x$ & $\mathrm{x}$ & & $x$ & & & \\
\hline Finca Doña Martina & $\mathrm{x}$ & $\mathrm{x}$ & & & $\mathrm{x}$ & & & & $\mathrm{x}$ \\
\hline C. del Arco & & $\mathrm{x}$ & & & & $\mathrm{x}$ & & & \\
\hline Los Mortolitos & & & & & $\mathrm{x}$ & & & & \\
\hline C. del Palomarico & & & & & $\mathrm{x}$ & & & & \\
\hline C. Perneras & & & & & $\mathrm{x}$ & & & & $\mathrm{x}$ \\
\hline Cejo del Pantano & & & & & $\mathrm{x}$ & & & & \\
\hline Hernández Ros & & & & & $\mathrm{x}$ & & & & \\
\hline C. de los Mejillones & & & & & & & & & $\mathrm{x}$ \\
\hline C. Bermeja & & & & & & & & & $\mathrm{x}$ \\
\hline C. del Caballo & & & & & & & & & $x$ \\
\hline C. del Algarrobo & & & & & & & & & $x$ \\
\hline Barranco de los Grajos & & & & & & & & & $x$ \\
\hline C. del Negro & & & & & $\mathrm{x}$ & & & & \\
\hline & & & AIGARVE CPR & RIUGAI & & & & & \\
\hline Vala & & & & & $\mathrm{x}$ & $x$ & & & \\
\hline Vale Boi & & $\mathrm{x}$ & $\mathrm{x}$ & & $\mathrm{x}$ & $\mathrm{x}$ & & & $\mathrm{x}$ \\
\hline
\end{tabular}

Tabla 2. Localizaciones del Paleolítico superior del sur de Iberia. (AR): Arte Rupestre; (AR+I): Industria lítica. 


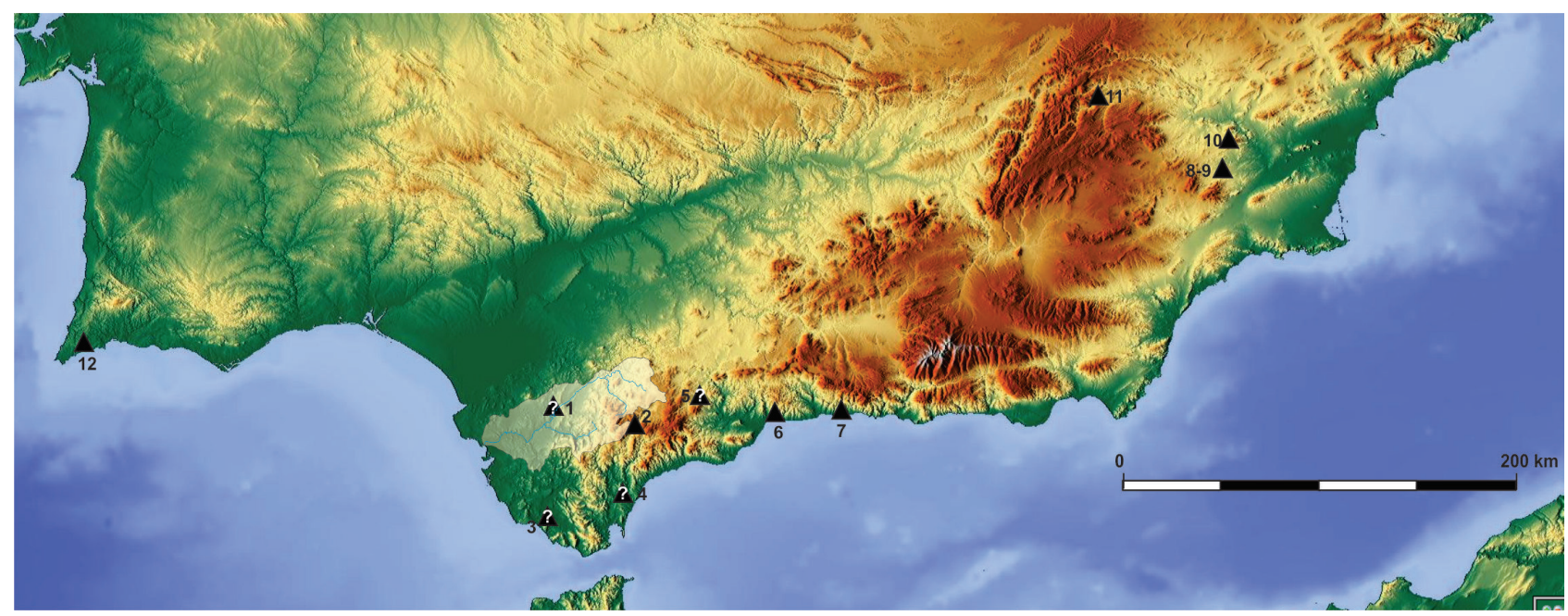

Figura 10. Localizaciones gravetienses en el sur de Iberia: 1. (?) Higueral de Valleja; 2. Pileta; 3. (?) Cueva de las Palomas IV; 4. (?) Cueva de las Estrellas; 5. (?) Ardales; 6. Bajondillo; 7. Cueva de Nerja; 8-9. La Boja, Finca de Doña Martina; 10. Cueva del Arco; 11. El Palomar; 12. Bale Voi.

de tres niveles adscritos a este tecno-complejo. La presencia de bordes abatidos, puntas gravetienses y micro-gravettes, junto con la alta presencia de piezas astilladas, son elementos análogos a otros yacimientos levantinos. El fenómeno de las piezas astilladas se ha relacionado con una posible tradición regional (Villaverde y Román, 2015) debido a sistemas de talla que han empleado el recurso al posado sobre yunque (de la Peña, 2011).

En la zona central de la región andaluza, se detecta en la cueva de Nerja un inicio de su ocupación en fechas entre 29-28 ka Cal. BP, con un conjunto industrial donde los productos laminares son los seleccionados para la confección de útiles retocados. Estos se encuadran en dos grupos, uno formado por los raspadores y piezas con retoques simples discontinuos y otro conformado por el utillaje de borde abatido: truncaduras y utillaje microlaminar, así como varios elementos de industria ósea, destacando un fragmento de punta de hueso con base ojival y dos puntas de base redondeada, así como varios elementos de adornos-colgante sobre moluscos marinos (Aura et al., 2010).

Dentro de la misma área central de Andalucía y también con carácter costero encontramos en el sitio de Bajondillo (Cortés, 2007) una ocupación atribuida al Gravetiense. En Bj10, aun siendo un nivel escaso en elementos retocados -en comparación con otras ocupaciones de la cavidad-, tanto las dataciones de $24 \mathrm{ka}$, como las características de este conjunto, con útiles de dorso abatido y truncaduras son de indudable raigambre grave- tiense. El nivel infrapuesto Bj 11, es interpretado por algunos autores cómo de posible clasificación gravetiense, atendiendo a la fecha de $26 \mathrm{ka}$, siendo complicado una asignación clara para este nivel desde el punto de vista tecno-cultural.

Ya hemos comentado la problemática de yacimientos como Zafarraya o la Cueva de Gorham para el mantenimiento de sus atribuciones dentro del Paleolítico superior temprano. Algo similar, a día de hoy, ocurre con la cueva de Higueral de Valleja, dentro de nuestra área de estudio. Aunque en este caso, con posibilidades de resolución a través de nuevos trabajos de campo que permitan una ampliación del conjunto lítico del nivel IV, un mejor conocimiento de la dinámica deposicional y la problemática estratigráfica de la secuencia, así como la realización de nuevas dataciones.

Un aspecto a tener en cuenta es la falta de dataciones directas sobre representaciones artísticas rupestres, que retrasen las cronologías claramente más allá del Solutrense. Se ha propuesto la existencia de fases pre-solutrenses, tanto a partir de análisis estilísticos (Balbín y Alcolea, 2006) como de la documentación de elementos que, con cierta solvencia, se pueden atribuir al Gravetiense. Es el caso de las manos en negativo en la cueva de Ardales (Cantalejo et al., 2004) o los recientes hallazgos de la Cueva de las Estrellas (Collado et al., 2019) en Castellar de la Frontera y Cueva de las Palomas (Fernández-Sánchez et al., 2019) en Facinas. Si bien es usual la relación entre este motivo y el periodo Gravetiense, nuevas dataciones nos 
hacen mantener cierta cautela, dado que se han propuesto incluso edades muy antiguas, insertas en el Paleolítico medio (Hoffmann et al., 2018) o muy cercanas a este (Pike et al., 2012). Aunque muy discutidas por gran parte de la comunidad científica (Aubert et al., 2018; Pearce y Bonneau, 2018; Pons-Branchu et al., 2020; Slimak et al., 2018; White et al., 2019), a esta cuestión se suma una datación en sentido contrario, es decir, dentro del periodo Solutrense, de una mano en negativo en la Cueva de Gorham (Simón et al., 2018), con una fecha de 20210-20750 Cal. BP y en relación directa con uno de los niveles de ocupación de la cavidad. Es por ello que es compleja una atribución sin reservas al periodo Gravetiense de estos motivos. Hoy día el indicio más sugerente a este respecto es la datación obtenida en un ejemplar de Ostrea edulis utilizado como lámpara en la Cueva de la Pileta (Cortés et al., 2016) cavidad que, dada la profusión de sus motivos y su amplia secuencia gráfica, alberga grandes posibilidades de obtención de datos que podamos relacionar directamente con este periodo.

En el Algarve Portugués, en la cueva de Vale Boi (Bicho et al., 2010), encontramos una de las secuencias más fiables para este periodo, abarcando hasta momentos Protosolutrenses. Análisis estadísticos bayesianos realizados sobre las dataciones, sugieren un comienzo del Gravetiense antiguo en el centro y sur de Portugal alrededor de 33 ka cal BP y terminando ca. 26.5 ka cal BP (Bicho et al., 2015), proponiéndose una recolonización de esta zona sur de Europa desde áreas meridionales, a modo de ola de avance. Esta se realizaría a través de los corredores costeros que, durante este periodo (Bicho et al., 2017), se abren en grandes llanuras costeras debido al descenso del nivel del mar. Esto junto con la apertura de paisajes que pierden su masa forestal debido a las fases más frías del Pleniglaciar Superior, son elementos que facilitarían una expansión y colonización del sur de la península Ibérica (Figura 11, Tabla 2).

\subsection{Solutrense}

La presencia de puntas tipo Vale Comprido, documentadas en Vale Boi (Bicho et al., 2010), en sustitución de las puntas de dorso características del Gravetiense, al igual que en otras localizaciones portuguesas, ha servido para la definición de un periodo transicional, conocido como Protosolutrense, visto cómo una continuidad poblacional y tecno-cultural entre las poblaciones Gravetienses y Solutrenses. Lejanas ya las visiones difusionistas y de recolonización del sur peninsular desde el área francesa, observamos que este proceso de solutrealización es difuso en el área mediterránea de la península Ibérica, siendo aún muy escasas las nuevas localizaciones fuera de la Extremadura portuguesa, aunque no inexistentes (Alcaraz et al., 2013). Algunos autores sugieren la asimilación de conjuntos del Solutrense inferior a esta fase Protosolutrense (Cascalheira y Bicho, 2015). Dentro de este esquema se encuadrarían cavidades cómo la cueva de Nerja, donde se insinúa la posibilidad de niveles transicionales entre el Gravetiense y el Solutrense (Aura et al., 2006). La visión en conjunto de estos datos confirman la continuidad poblacional en la Península en momentos muy fríos, coincidiendo con el Evento Heinrich 2, sirviendo como área refugio durante este periodo (Straus, 2015) y reflejándose en la amplitud de yacimientos que ahora veremos para el sur peninsular.

El fenómeno del Solutrense ha llamado la atención de numerosos investigadores debido a la clara ruptura que se produce con la dinámica paneuropea de las secuencias tecno-culturales previas. Las diferentes estrategias de adaptabilidad, así como la desocupación de algunas áreas septentrionales durante el Último Máximo Glacial en Europa, produce un proceso de regionalización en los diferentes tecnocomplejos, entendidos estos cómo procesos de adaptación, en el que surge el fenómeno del Solutrense caracterizado principalmente por la aparición de puntas realizadas con retoque plano invasivo en el Suroeste francés y la península Ibérica.

Una vez terminada la discusión sobre la posible relación entre el Ateriense y el Solutrense, que durante tantos años focalizó parte del debate sobre el Solutrense (Obermaier, 1985; Otte, 1997; Pericot, 1942; Tiffagom, 2005), dada la discordancia de las cronologías africanas así como las notables diferencias entre ambos tecnocomplejos (Alcaraz, 2007). Hoy día la cuestión radica más en la validación del sistema tripartito establecido desde la región francesa (Smith, 1966), que con matizaciones y particularidades aún se mantiene como modo de entender la secuencia. En el sistema tripartito se plantea un Solutrense inferior, pleno y superior que finaliza en el área mediterránea con una fase solutreo-gravetiense en la que se pierden los rasgos solutrenses (Fullola, 1976; Jordá, 1955; Pericot, 1942; Ripoll, 1988; Zilhão, 1994). Este esque- 


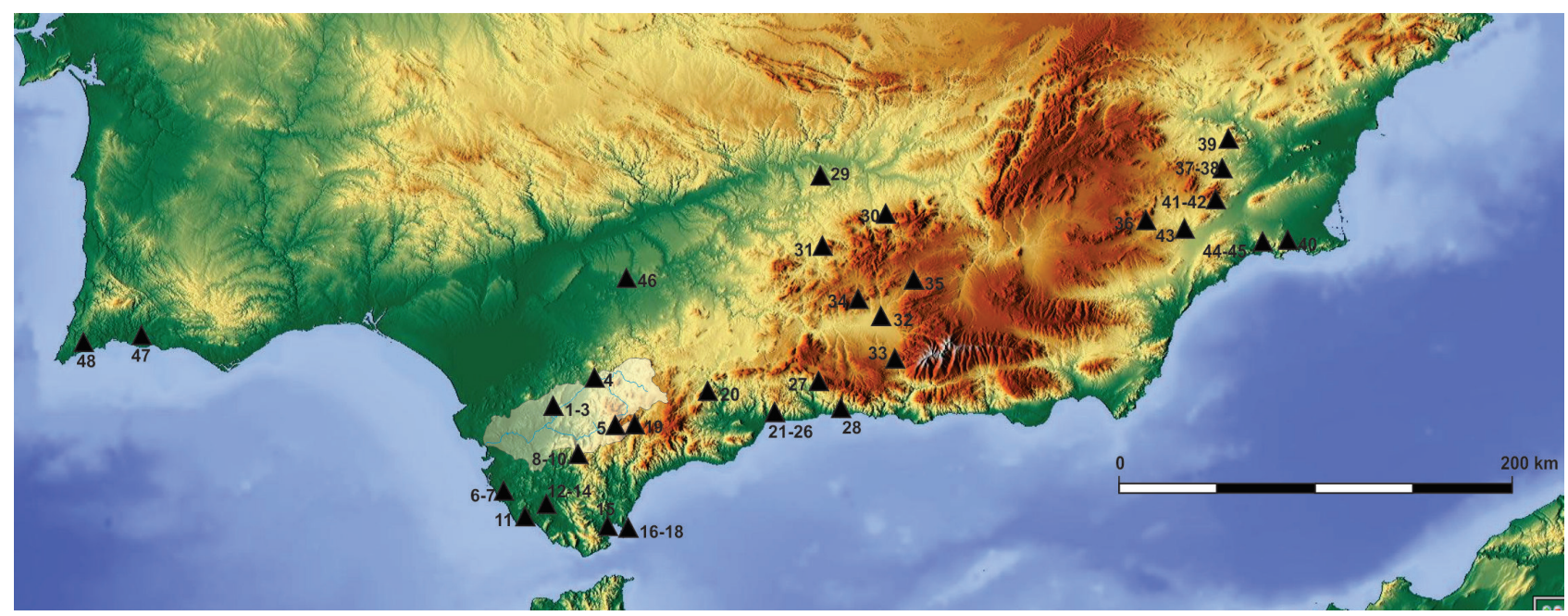

Figura 11. Localizaciones solutrenses del sur de Iberia: 1-3. Higueral de Valleja, Escalera 3, Llanos de Don Pedro; 4. La Toleta; 5. VR-15; 6-7. La Fontanilla, Casa de postas; 8-10. Cueva de las Motillas, Higueral-La Guardia, Cueva de los Márquez; 11. Cueva del Moro; 12-14. Cueva de las Palomas, Cueva de Levante, Tajo de las Figuras; 15. Torre del Amirante; 16-18. Cueva de Gorham, Sewell, Martin; 19. La Pileta; 20. Ardales; 21-26. Bajondillo, Complejo del Humo, Navarro IV, Hoyo de la Mina, Higuerón, Cueva Victoria; 27. Zafarraya; 28. Cueva de Nerja; 29. Peña Grieta; 30. El Morrón;

31. El Pirulejo; 32. Pantano de Cubillas; 33. Cueva de los Ojos; 34. Malalmuerzo; 35. Cueva de las Ventanas; 36. Cueva Ambrosio; 37-38. La Boja, Finca de Doña Martina; 39. Cueva del Arco; 40. Cueva del Negro. 40-41. Los Mortolitos, Cejo del Pantano. 44-45. El Palomarico, Hernández Ros. 46. Los Álamos. 47. Vala. 48. Vale Boi.

ma se propone a través de la ausencia o presencia de diferentes tipos de puntas foliáceas: puntas de cara plana para el Solutrense inferior, puntas bifaciales de hoja de laurel para el Solutrense pleno y elementos con aletas y pedúnculos, así como puntas de escotadura para el Solutrense superior o evolucionado. Para este último, a su vez, se ha propuesto una división tripartita: fase I con predominio de puntas de aletas y pedúnculos tipo Parpalló y fases II y III con la sustitución de éstas por puntas de escotadura (Fortea y Jordá, 1976), también denominado Solutreo-gravetiense (Fullola, 1978). Un reciente trabajo, a través del análisis estadístico bayesiano de las fechas del área Mediterránea, pone en entredicho este esquema debido al solapamiento cronológico de las fases propuestas, sobre todo entre el Solutrense pleno y superior (Cascalheira y Bicho, 2015).

Durante este periodo se observa un amplio poblamiento en el sur de la península Ibérica, caracterizado sobre todo por el predominio de yacimientos con elementos pedunculados y aletas tipo Parpalló, así como puntas de escotadura, lo que normativamente se viene atribuyendo al Solutrense superior o evolucionado. Este fenómeno podría ponerse en relación con una respuesta de carácter funcional hacia estrategias de subsistencia de carácter regional en el sur de la península Ibérica a lo largo del Último Máximo Glacial, relacionadas con una profusa utilización del arco y la flecha (Muñoz-Ibáñez, 2000).

Niveles adscritos al Solutrense inferior se han documentado en el abrigo murciano de La Boja (Zilhão et al., 2017) donde se documenta un conjunto de puntas de cara plana unifacial y un fragmento de foliáceo. La secuencia continúa con un Solutrense pleno escasamente representado por algunas lascas con adelgazamiento bifacial y un fragmento de foliáceo, fechado entre 24-25 ka BP y un Solutrense superior representado con puntas de escotadura y un posible foliáceo con una fecha de 23 ka BP. Finaliza este periodo con un nivel adscrito al Solutreo-gravetiense a partir de la presencia de piezas apuntadas hechas sobre lámina, con una fecha de 17-16 ka BP (Lucena et al., 2012). El abrigo de Finca Doña Martina presenta dos niveles adscritos al Solutrense superior, la Unidad 4 con puntas de escotaduras (22-23 ka BP) y la Unidad 5 con puntas de aletas y pedúnculo. Estos yacimientos vienen a revalorizar el papel de la región para estos momentos, un área geográfica en la que hasta hoy las referencias a ocupaciones solutrenses 
eran parcas, remontándose muchas de ellas a los trabajos de Louis Siret: Cueva de la Moneda, Cejo del Pantano, Los Mortolitos, Rincón de Yéchar, Cueva del Palomarico, Cueva de las Perneras, Cueva de Hernández Ros, Cueva de los Tollos, Cueva Bermeja y Cueva de las Palomas, sitios recogidos en el trabajo de Carmen Cacho Quesada (Cacho, 1981). A estos se suma el hallazgo de foliáceos y hojas de laurel en la Cueva del Negro (Martí-Andreu, 2007), más los hallazgos de la Cueva del Arco en Cieza, aún en proceso de investigación, pero con la presencia de arte rupestre y elementos cómo una punta de escotadura propia del Solutreo-gravetiense (Martín-Lerma et al., 2020).

Cueva Ambrosio en la provincia de Almería, es uno de los yacimientos clave para este periodo dentro del sur peninsular, con una amplia secuencia del Solutrense superior (Ripoll, 1988) y pleno (Ripoll et al., 2006), con fechas entre 23-20 ka Cal BP y de 26 ka Cal BP respectivamente, siendo esta última la más antigua para el periodo en el territorio peninsular. Cuenta el sitio además, con representaciones rupestres que han podido ser fechadas a partir de su correlación estratigráfica con los niveles sedimentarios que las cubrían (Ripoll et al., 2013). Asimismo, en la provincia de Granada contamos con los yacimientos de Pantano de Cubillas (Toro y Almohalla, 1979), Cueva de Malalmuerzo (Cantalejo, 1983) con representaciones rupestres que han sido atribuidas al Solutrense; en la Cueva de las Ventanas, aunque descontextualizados, se localizaron elementos foliáceos (Sánchez-Tarifa, 2004) y un reciente trabajo presenta un conjunto homogéneo de un sector de la cavidad (Riquelme et al., 2020).

En el interior, contamos con la presencia en Jaén de las localizaciones adscritas al Solutrense de la Peña de la Grieta de Porcuna (Arteaga et al., 1993) y cueva del Morrón (Sanchidrián, 1982; Sanchidrián et al., 2017) y en El Pirulejo de Priego de Córdoba, con niveles definidos dentro del Solutrense evolucionado o Solutreo-gravetiense con presencia de puntas de escotadura (Cortés et al., 2008). En la provincia de Sevilla, recientemente ha sido hallada una localización al aire libre en la cuenca del río Corbones denominada Los Álamos, que cuenta con la presencia de puntas unifaciales y pedunculadas (Gavilán et al., 2020).

El área de la costa de Málaga parece convertirse en uno de los centros vertebradores de la ocupación humana para este territorio, contando con buen número de localizaciones y una larga tradición de investigaciones. Destaca, a este res- pecto la Cueva de Bajondillo por la aplicación de análisis multidisciplinares en toda su secuencia (Cortés, 2007), que aunque en cuestiones puntuales discutida, no deja de ser un referente para el Paleolítico medio y superior de la región andaluza. Los niveles $\mathrm{Bj} / 6$ a Bj/9 (Cortés et al., 2007) están adscritos al Solutrense pleno (21-18 Cal ka BP) $\mathrm{y}$ al Solutrense superior (18-16 ka Cal BP). En la cueva de Nerja se ha propuesto una secuencia con inicios en el Solutrense inferior, continuidad en el Solutrense Pleno con fechas alrededor de 21 ka y finalizando con el Solutrense superior evolucionado de facies ibérica datado entre 16-17 ka (Aura et al., 2004). En esta cavidad, considerada uno de los grandes santuarios rupestres de Andalucía, fue fechado un cérvido en $19.990 \pm 210$ BP (Sanchidrián y Márquez, 2003), así como restos de carbones de Pinus, en lo que se interpreta como una lámpara o punto de iluminación fijo en 22490-22345 Cal. BP (Medina et al., 2019). En la secuencia del Abrigo 6/Complejo del Humo se inserta un nivel definido como Solutrense pleno (Ramos-Fernández, 2006) y en el Abrigo 4 del mismo complejo, fueron documentados elementos solutrenses (Ramos-Fernández y Durán, 1988). Otras localizaciones con elementos líticos de este periodo son: Hoyo de la Mina (Ferrer et al., 2006), Higuerón (Cacho y López, 1979), Zafarraya (Barroso y Lumley, 2006), mientras que para Cueva Navarro IV (Sanchidrián, 1981) y Cueva Victoria (Cantalejo et al., 2007) se han propuesto asignaciones solutrenses de algunas de sus representaciones rupestres.

Hacía el interior malagueño destacan dos grandes santuarios rupestres. Cueva de Ardales donde la fase más amplia descrita (Fase II) ha sido propuesta para momentos Solutrenses (Cantalejo et al., 2006). Recientes excavaciones han documentado dentro de una secuencia que abarca hasta el Paleolítico medio tardío, un nivel, aunque poco diagnóstico con datación dentro de la "horquilla solutrense" de 19,239 \pm 126 cal BP (Ramos et al., 2019). Cueva de la Pileta, en la Serranía de Ron$\mathrm{da}$, dispone para esta fase del primer resultado de cronología absoluta sobre arte rupestre paleolítico del Suroeste, una datación directa del pigmento carbonoso mediante la técnica del C14 por AMS, del Solutrense pleno-evolucionado, muestreada en una conocida figura de uro. Finalmente, dentro de éste área, se ha barajado la posible filiación solutrense (o de inicios del Magdaleniense) de las contadas representaciones de la Cueva del Gato (Cantalejo et al., 2006). 
En la cavidad de Higueral de Motilla, entre las provincias de Cádiz y Málaga, estudios realizados en la década de los 90 pusieron de manifiesto la existencia de conjuntos líticos en posición estratigráfica pertenecientes al Solutrense superior (Giles et al., 1997). Recientes intervenciones de carácter sistemático han corroborado esta atribución (Torres et al., 2012). En la Cueva de las Motillas ya desde los años 80 se apuntaba la atribución Solutrense de alguna de sus manifestaciones gráficas (Santiago-Vilches, 1990), así como los nuevos motivos documentados en la vecina Cueva de los Márquez (Medina et al., 2019). En la Sierra de Grazalema, en la Cavidad VR-15 de Villaluenga, podemos contar con la asignación a un Solutrense pleno-superior y a fases finales del Solutrense de varios de sus motivos rupestres (Fernández-Sánchez et al., 2017).

En Gibraltar ya hemos señalado la existencia de un nivel adscrito al Solutrense superior en la Cueva de Gorham (Gutiérrez-López et al., 2012), presentando dataciones de 22 y 19 ka Cal BP con puntas de escotadura, de aletas y pedúnculo, así como arte asociado, contando con la datación de un negativo de mano en negro dentro de la misma fase. Otra localización gibraltareña es Sewell's Cave, excavada en el siglo XIX, pero de cuyo estudio reciente de las colecciones conservadas se desprende una ocupación dentro del Solutrense superior, con puntas pedunculadas y de escotadura. (Giles et al., 2000). Nuevos motivos rupestres documentados en Martin's Cave han sido considerados dentro de este periodo (Simón et al., 2019). En el mismo ámbito geográfico, en la Bahía de Gibraltar, encontramos un conjunto atribuido al Solutrense en Torre del Almirante en Algeciras (Castañeda y Herrero, 1998), completándose el registro del área del Estrecho con varias representaciones rupestres que tradicionalmente se vienen atribuyendo al Solutrense, como los équidos de la Cueva del Moro (Mas et al., 1995) y Cueva de las Palomas I (Cabré, 1915; Fortea, 1978).

En la vertiente Atlántica de Cádiz, un claro ejemplo de asentamiento Solutrense al aire libre lo encontramos en La Fontanilla, con presencia de puntas de retoque plano y pedunculadas que lo encuadran dentro del Solutrense superior (Ramos et al., 2014), con dataciones por TL de 17 ka (Castañeda et al., 2020).

Para finalizar, en el extremo suroccidental de la Península, dentro de la secuencia de Vale Boi como ya apuntábamos, contamos con la presencia de niveles adscritos al Proto-solutrense, con la particu- laridad de una aparición muy temprana de puntas de aletas y pedúnculo, adscritas normativamente al Solutrense superior. El contexto del que proceden posee fechas de $24.5 \mathrm{ka}$ cal BP y están presentes en toda la secuencia. Esta finaliza con una cronología de 20.3 ka cal BP, observándose un aumento de la presencia de puntas de escotadura propias de la fase final Solutreo-gravetiense (Bicho et al., 2010; Cascalheira, 2010; Cascalheria et al., 2012).

\subsection{Magdaleniense}

La finalización paulatina del Último Máximo Glacial, supone a nivel peninsular una expansión de los hábitats hacia zonas hasta ahora inhabitadas o escasamente ocupadas. Sin embargo, para el área meridional de Iberia supone una ruptura, al menos con los datos que manejamos hoy día, en las secuencias de ocupación de las cavidades y del territorio (Figura 12, tabla 2). Se observa claramente un intervalo temporal y estratigráfico que abarca las primeras fases del periodo, a excepción de los niveles del Magdaleniense medio mediterráneo en el yacimiento cordobés de El Pirulejo $(14250 \pm 90$ Cal BP y $17458 \pm 257$ Cal BP) (Cortés et al., 2014), con industrias de carácter microlaminar, sin la presencia de elementos geométricos y las últimas fechas dadas (16200-14430 ka) para nuevos conjuntos de la Cueva de Malalmuerzo (Cabello et al., 2020). En los niveles suprayacentes de El Pirulejo se han detectado conjuntos pertenecientes al Magdaleniense superior mediterráneo y Magdaleniense superior final mediterráneo (Cortés et al., 2008). Este parco registro puede comenzar a sumar alguna localización, como es el caso del Tajo de los Marchales, aun sin dataciones, donde se propone la presencia de un Magdaleniense antiguo a partir de la caracterización tecno-tipológica (García-Franco y Morgado, 2016, 2018).

En la Región de Murcia dentro del Magdaleniense superior se han encuadrado diversos sitios: Barranco de los Grajos, Cueva Bermeja, Cueva Perneras, Cueva del Caballo, Cueva de los Mejillones y Cueva del Algarrobo. (Martínez-Andreu, 1989). En Finca de Doña Martina se ha propuesto una ocupación Epimagdaleniense con una ocupación caracterizada por utillaje microlaminar de dorso y raspadores (Román et al., 2013).

En la cueva de Nerja, los niveles magdalenienses están bien representados en su etapa superior, con dataciones que oscilan entre los $12 \mathrm{ka} \mathrm{BP}$ con presencia de escalenos y arpones hasta el epimag- 


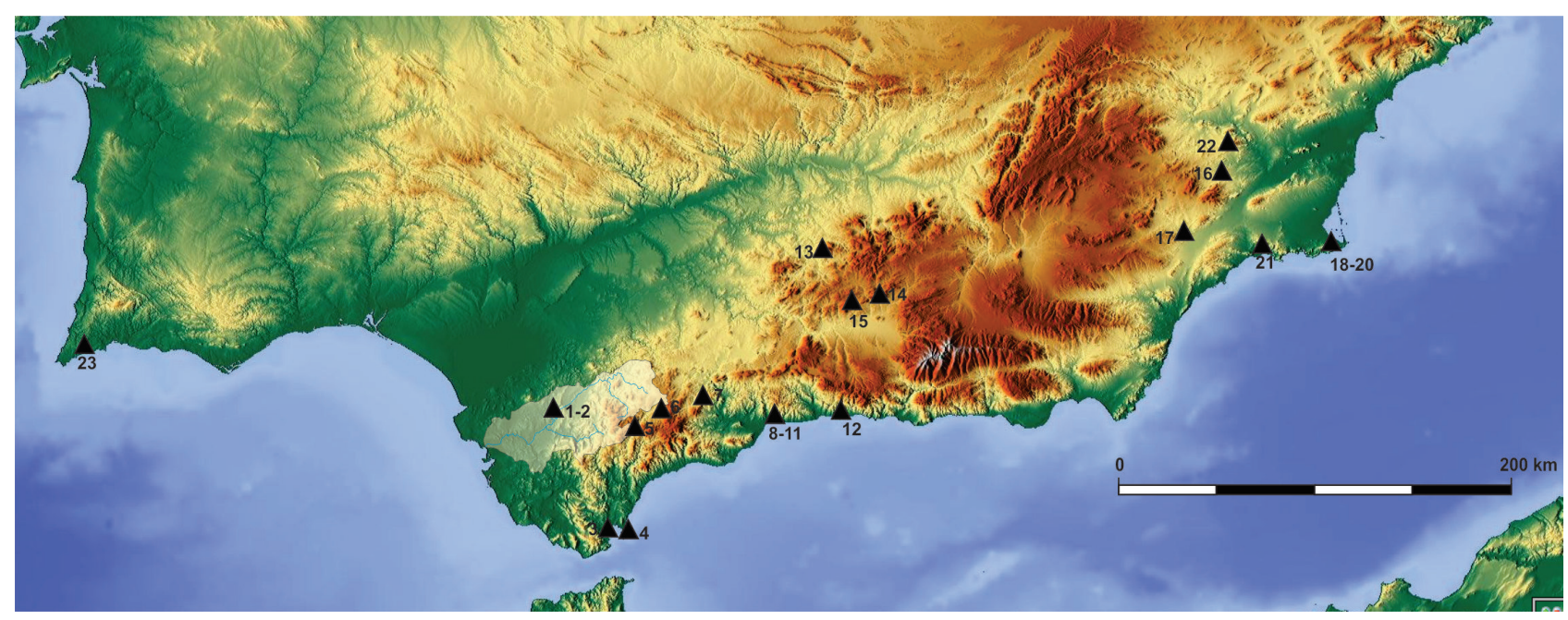

Figura 12. Localizaciones magdalenienses del sur de Iberia: 1-2. Las Arenosas, Los Frailes; 3. Palmones; 4. Cueva de Gorham; 5. La Pileta; 6. El Duende; 7. Ardales; 8-11. Complejo del Humo, Higuerón, Hoyo de la Mina, Cueva Tapada; 12. Cueva de Nerja; 13. El Pirulejo;

14. Tajo de los Marchales 15. Malalmuerzo; 16. Finca de Doña Martina; 17. Cueva Perneras; 18-20. Cueva de los Mejillones, Cueva Bermeja, Cueva del Caballo; 21. Cueva del Algarrobo.

22. Barranco de los Grajos. 23. Vale Boi.

daleniense datado en 10 ka BP (Aura, 1995). Por otro lado, atendiendo al carácter de santuario rupestre de la cavidad, la secuencia propuesta desde el punto de vista tecno-estilístico contempla una importante fase dentro del Magdaleniense superior (Sanchidrián, 1994). Otras localizaciones malagueñas en las que se ha sugerido una ocupación durante el Magdaleniense superior, con un registro desigual, son Hoyo de la Mina, Abrigo 4 y 6 del Complejo del Humo, El Duende, Cueva del Higuerón y Cueva Tapada.

Dentro de la secuencia gráfica de Ardales se ha propuesto la existencia de un ciclo final en el que se incluiría la fase Magdaleniense, caracterizado por zoomorfos y figuras femeninas (Cantalejo et al., 2005; Ramos et al., 2002), al igual que en la cueva de la Pileta donde se han documentado e interpretado varios horizontes cómo pertenecientes a este periodo (Sanchidrián, 1997).

En Gibraltar, la cueva de Gorham presenta, dentro del subnivel IIIa, una ocupación poco diagnóstica, caracterizada por el dominio de buriles y raspadores junto con láminas de dorso abatido, encuadradas dentro de un rango de fechas entre 11-13 ka BP, que la fija en un Magdaleniense superior de tipo mediterráneo. Finalizando el recorrido en el Algarve portugués, el Abrigo de Vale Boi es la estación paleolítica que representa la ocupación humana durante el Magdaleniense final (Bicho et al., 2010).

\section{Conclusiones}

Si bien los conjuntos presentados dentro de la cuenca del Guadalete para el Paleolítico superior presentan una información desigual, son suficientes para aportar una visión de conjunto al marco general de las ocupaciones del área meridional de la península Ibérica, poniendo de relieve las singularidades de esta región.

Una revisión crítica de los datos aportados para los momentos iniciales del Paleolítico superior nos muestran un panorama muy escaso en cuanto a las ocupaciones atribuibles claramente al Auriñaciense, sólo representado con claridad y para momentos tardíos, en el área de claras influencias levantinas de Murcia, coincidiendo este periodo con la perduración tardía de los neandertales en el sur de la península Ibérica. No es hasta el Gravetiense cuando se observa una clara aunque aún muy dispersa, ocupación de la región, abriéndose la posibilidad, a falta de confirmación, de una ocupación de este periodo en la cueva de Higueral de Valleja.

Durante el Solutrense los asentamientos del sur peninsular se intensifican de una manera muy clara, coincidiendo con eventos de empeoramiento climático dentro del Último Máximo Glacial, influyendo el carácter de refugio termófilo de esta región (González-Sampériz et al., 2010). Esto favorece, junto a las innovaciones adaptativas del 
Solutrense, una expansión de las poblaciones de HAM. Destaca la escasez de registros relacionados con niveles inferiores o transicionales dentro del Solutrense, y será en momentos adscritos normativamente al Solutrense pleno y sobre todo al superior, cuando encontremos los núcleos de asentamientos bien establecidos en el sur de la península Ibérica. Este fenómeno puede ser debido a un escaso sustrato poblacional gravetiense. Por otro lado, se vislumbra que este periodo de transición entre el Gravetiense y el Solutrense, tiene características propias en esta región, como la ausencia de elementos encuadrables en el Protosolutrense que serían sustituidos por los niveles del Solutrense antiguo que, aunque sólo escasamente representados en Nerja y en el abrigo de La Boja, avalan la continuidad poblacional en la región. La posibilidad de una pronta adopción y expansión de las puntas de tipo Parpalló, cómo se observa en la secuencia de Vale Boi y Cueva Ambrosio con los foliáceos bifaciales, nos indican una nueva particularidad de la dinámica crono-cultural del sur peninsular que dificulta su encuadre dentro del desarrollo trifásico del área levantina mediterránea.

Los modelos de ocupación solutrenses parecen responder a concentraciones en diferentes áreas-núcleos intensamente ocupados a lo largo de la costa mediterránea, destacando a este respecto en el sur peninsular el área de Málaga. Desde aquí proponemos la existencia de un núcleo de ocupación solutrense en el área de Cádiz (Tabla 1), en este caso con fuerte carácter ribereño, siendo la cuenca del Guadalete el eje vertebrador entre las áreas de sierra y la costa. Esta área estaría conformada por los yacimientos directamente asociados a la cuenca del Guadalete donde encontramos una mayor concentración de áreas frecuentadas durante este periodo. En relación directa con estos asentamientos estarían los santuarios rupestres de Cueva de la Motilla y Cueva de los Márquez, así como la cueva VR15 en la Sierra de Grazalema, situada a pocos kilómetros de la Cueva de la Pileta, gran santuario rupestre de Andalucía occidental. Éste tipo de santuarios rupestres, son interpretados por algunos autores como áreas de agregación (Conkey, 1980; Ramos et al., 1999; Utrilla, 1994), siendo muy sugerente su localización equidistante entre el núcleo solutrense malagueño y el gaditano, cuyos paralelos iconográficos han sido recientemente expuestos entre la Cueva de los Márquez en Cádiz y Cueva de la Pileta, Nerja y Cueva de Navarro IV (Medina et al., 2019).
Durante el Tardiglaciar, en momentos Magdalenienses, el panorama es, a día de hoy, difuso en el área meridional de la Península, con vacíos geográficos y cronológicos, abarcando, sobre todo, las primeras fases de este periodo. Representado en el área del Guadalete por las localizaciones de las Arenosas, junto tal vez a La Escalera 1 y Los Frailes, donde hay que tener en cuenta su naturaleza de conjuntos de superficie poco diagnósticos. A este respecto, no se descarta que la Cueva de Higueral de Valleja pueda albergar niveles de ocupación de este periodo.

La cuenca del Guadalete se muestra como un sitio clave para la comprensión de las poblaciones paleolíticas en el sur de la península Ibérica, pudiendo ser un punto esencial en cuestiones como la transición Paleolítico medio-Paleolítico superior, las primeras ocupaciones en época gravetiense o los modelos de desarrollo del Solutrense en el sur peninsular. Teniendo en todo ello un papel fundamental, la necesidad de la intensificación de las investigaciones en la Cueva de Higueral de Valleja asumiendo que todos los datos que conocemos hoy día, son el resultado de una excavación y un muestreo en una intervención de apenas $3,75 \mathrm{~m}^{3}$.

\section{Bibliografía}

ALCARAZ CASTAÑO, Manuel. 2007: "El Ateriense del Norte de África y el Solutrense peninsular: ¿contactos transgibraltareños en el Pleistoceno Superior?". Munibe, 58, pp. 101-126.

ALCARAZ CASTAÑO, Manuel; ALCOLEA GONZÁLEZ, José J.; DE BALBÍN BEHRMANN, Rodrigo; GARCÍA VALERO, Miguel A.; YRAVEDRA SAINZ DE LOS TERREROS, José; BAENA PREYSLER, Javier 2013: “Los orígenes del Solutrense y la ocupación pleniglaciar del interior de la península Ibérica: implicaciones del nivel 3 de Peña Capón (Valle del Sorbe, Guadalajara)". Trabajos de Prehistoria, 70(1), pp. 28-53. https://doi.org/10.3989/tp.2013.12101.

ANDERSON, Lars; REYNOLDS, Natasha; TEYSSANDIER, Nicolas. 2019: "No reliable evidence for a very early Aurignacian in Southern Iberia". Nature Ecology \& Evolution, 154, p. 713. https://doi.org/10.1038/s41559-019-0885-3.

ANGELUCCI, Diego E.; ZILHÃO, João. 2009. "Stratigraphy and formation processes of the Upper Pleistocene deposit at Gruta da Oliveira, Almonda Karstic System, Torres Novas, Portugal”. Geoarchaeology, 24, pp. 277-310. 
ARTEAGA, Oswaldo; NOCETE, Francisco; RAMOS, José; ROOS, Ana María. 1993: "Reconstrucción del proceso histórico en la ciudad ibero-romana de Obulco". En Junta de Andalucía (ed.): Investigaciones Arqueológicas en Andalucía. Proyectos, pp. 809-814. Consejería de Cultura y Medio Ambiente. Sevilla.

AURA TORTOSA, Joan Emili. 1995: El Magdaleniense mediterráneo: La cova del Parpalló. Servicios de Investigación Prehistórica. Serie de Trabajos Varios (vol. 91). Diputación de Valencia. Valencia.

AURA TORTOSA, Joan Emili; JORDÁ, Jesús; FORTEA, Francisco. 2006: "Cueva de Nerja (Málaga, Spain) y los inicios del Solutrense en Andalucía". Zephyrus, LIX, pp. 67-88. https://doi. org/10.1111/j.1439-0485.2009.00333.x.

AURA TORTOSA, Joan Emili; JORDÁ PARDO, Jesús; AVEZUELA ARISTU, Bárbara; PÉREZ RIPOLL, Manuel; TIFFAGOM, Marc; MORALES PÉREZ, Juan Vicente. 2010: "La Cueva de Nerja (Málaga, España) y el Gravetiense en Andalucía”. En E. MATA ALMONTE (coord.): Cuaternario y Arqueología: Homenaje a Francisco Giles Pacheco, pp. 125-145. Asociación Profesional del Patrimonio Histórico-Arqueológico de Cádiz (ASPHA) y Servicio de Publicaciones de la Diputación Provincial de Cádiz. Cádiz.

BAENA PREYSLER, Javier; MORGADO RODRÍGUEZ, Antonio; LOZANO RODRÍGUEZ, José Antonio; TORRES NAVAS, Concepción; ALCALÁ ORTÍZ, Antonio, BERMÚDEZ CANO, Rafael; BÉRMUDEZ JIMÉNEZ, Francisco; RUIZ-RUANO COBO, Francisco. 2012: "Titanes en el complejo Motillas. La secuencia del Pleistoceno Superior de la Cueva del Higueral-Guardia en las Béticas Occidentales (Proyecto Kuretes)". Menga. Revista de Prehistoria de Andalucía, 3, pp. 107-117.

BALBÍN BERHMANN, Rodrigo de; BUENO RAMÍREZ, Primitiva; ALCOLEA GONZÁLEZ, José J.; BARROSO BERMEJO, Rosa; ALDECOA QUINTANA, Amparo; GILES PACHECO, Francisco; FINLAYSON, J. Clive, SANTIAGO PÉREZ, Antonio. 2000: "The engravings and Palaeolithic paintings from Gorham's Cave". En C. FINLAYSON, G. FINLAYSON y D. FA (eds.): Gibraltar during the Quaternary. The southernmost part of Europe in the last two million years, pp. 170196. Government Heritage Publications Monographs 1. Gibraltar.

BALBÍN BERHMANN, Rodrigo de; ALCOLEA GONZÁLEZ, José J. 2006: "Arte paleolítico en los confines de Europa: Cuevas al aire libre en los confines del sur de la península Ibérica". En J. L. SANCHIDRIÁN, A. Mạ. MÁRQUEZ y J. M. FULLOLA (eds.): La cuenca mediterránea durante el Paleolítico superior. 38.000-10.000 años. Reunión de la VIII Comisión del Paleolítico superior. IV Simposio Cueva de Nerja. U. I. S. P. P, pp. 118-138. Fundación Cueva de Nerja. Málaga.

BARROSO, Cecilio; DE LUMLEY, Henry. 2006: La Grotte du Boquete de Zafarraya (Malaga, Andalousie). Consejería de Cultura, Junta de Andalucía. Sevilla.

BARTON, R. Nicholas E. y JENNINGS, Richard P. 2013: "The lithic artefact assemblage of Gorham's Cave". En N. BARTON, C STRINGER y C. FINLAYSON (eds.): Neanderthals in context. A report of the 1995-1998 excavations at Gorham's and Van and Vanguard Caves, Gibraltar, pp. 151-187. Oxford University School of Archaeology: Monograph 75. Institute of Archaeology, University of Oxford. Oxford.

BERNAL-CASASOLA, Dario; SALOMON, Ferréol; DÍAZ, José Juan; LARA, Macarena; RIXHON, Gilles; MORALES, Jacob; VIDAL-MATUTANO, Paloma. 2020: “Deeper Than Expected: The Finding of a Remarkable Ancient Harbour at Gadir/Gades and an Exceptional Sedimentary Archive (Cádiz, Southern Spain)". Journal of Maritime Archaeology, 15, pp. 165183. https://doi.org/10.1007/s11457-02009258-w.

BICHO, Nuno; MANNE, Tiina; CASCALHEIRA, João; MENDOÇA, Carolina; ÉVORA, Marina; GIBAJA, Juan F.; PEREIRA, Telmo. 2010: "O Paleolitico superior do sudoeste da península Ibérica: o caso do Algarve. The Upper Paleolithic of Southwestern Iberia: the case of Algarve". En X. MANGADO (coord.): El Paleolítico Superior Peninsular. Novedades del Siglo XXI, pp. 215-234. Universidad de Barcelona. Barcelona.

BICHO, Nuno; GIBAJA, Juan F.; STINER, Mary; MANNE, Tiina. 2010: "Le paléolithique supérieur au sud du Portugal: le site de Vale Boi “. Anthropologie, 114(1), pp. 48-67. https://doi. org/10.1016/j.anthro.2010.01.002.

BICHO, Nuno; MARREIROS, Joao; CASCALHEIRA, Joao; PEREIRA, Telmo; HAWS, Jonathan 2015: "Bayesian modeling and the chronology of the Portuguese Gravettian". Quaternary International, 359-360, pp. 499-509. https://doi.org/10.1016/j.quaint.2014.04.040.

BICHO, Nuno; CASCALHEIRA, Joao; GONÇALVES, 
Carolina, 2017: "Early Upper Paleolithic colonization across Europe: Time and mode of the Gravettian diffusion".PLoSONE,12(5).https:// doi.org/10.1371/journal.pone.0178506.

CABELLO-LIGERO, Lidia; CANTALEJO, Pedro; ESPEJO, María de Mar; BUENDÍA, Antonio F; FERNÁNDEZ, José M.; GONZÁLEZ RÍOS, Manuel; GONZÁLEZ, Olga; DURÁN, Juan José; ROBLEDO, Pedro; AVEZUELA, Bárbara; JORDA PARDO, Jesús F.; UZQUIANO, Paloma; RIQUELME, José Antonio; RUIZ-ZAPATA, Blanca; GIL-GARCÍA, María J.; RAMOS-MUÑOZ, José; WENIGER, Gerd-Christian; PALOMO, Alfonso; SMITH, Víctor Manuel; BECERRA, Serafín; SALVADOR FERNÁNDEZ, Diego; DOMÍNGUEZ-BELLA, Salvador; TAFELMAIER, Yvonne; VIJANDE-VILA, Eduardo. 2020: "New Archaeological Data on the Upper Paleolithic Site of Cueva de Malalmuerzo (Moclín, Granada, Spain)." Munibe Antropologia-Arkeologia, 71. https://doi. org/10.21630/maa.2020.71.07.

CABRÉ AGUILÓ, Juan. 1915: El arte rupestre en España (regiones septentrional y oriental). Memorias de la Comisión de Investigaciones Paleontológicas y Prehistóricas, 1. Museo Nacional de Ciencias Naturales. Madrid.

CACHO QUESADA, Carmen y LÓPEZ, Pilar. 1979: "La Cueva del Higuerón (Málaga). Estudio de sus materiales". Trabajos de Prehistoria, 36/1, pp. 11-82.

CACHO QUESADA, Carmen. 1981: El Paleolítico superior en el Sureste de la península Ibérica. Tesis Doctoral. Universidad Complutense de Madrid. Madrid.

CANTALEJO DUARTE, Pedro. 1983: "La Cueva de Malalmuerzo, Moclín, Granada". Antropología y Paleoecología Humana, 3, pp. 59-93.

CANTALEJO DUARTE, Pedro; MAURA, Rafael; ESPEJO, María del Mar; RAMOS, José; MEDIANERO, Francisco J.; ARANDA, Antonio; CASTAÑEDA, Vicente; CÁCERES, Isabel. 2004: "Cueva de Ardales (Málaga): testimonios gráficos de la frecuentación por formaciones sociales de cazadores-recolectores durante el Pleistoceno Superior. En C. SÁNCHEZ DE LAS HERAS (coord.): Sociedades recolectoras y primeros productores: actas de las Jornadas Temáticas Andaluzas de Arqueología (Ronda, 28 al 30 de octubre de 2003), pp. 123-138. Consejería de Cultura. Ronda.

CANTALEJO DUARTE, Pedro; MAURA MIRAJES, Rafael; ESPEJO HERRERÍAS, Maria del Mar;
RAMOS-MUÑOZ, José; MEDIANERO, Francisco; ARANDA CRUCES, Antonio. 2005: "Investigación sobre las manifestaciones gráficas conservadas en la cueva de Ardales (Málaga), durante los años 2002- 2005”. En C. SÁNCHEZ (ed.): Actas I Jornadas de Patrimonio de Guadalteba, pp. 207-218. Junta de Andalucía.

CANTALEJO DUARTE, Pedro; MAURA, Rafael; ESPEJO, María del Mar; RAMOS, José F.; MEDIANERO, Javier; ARANDA, Antonio; DURÁN, Juan J. 2006: Cueva de Ardales: Arte prehistórico y ocupación en el Paleolítico Superior. Diputación de Málaga. Málaga.

CANTALEJO DUARTE, Pedro; BECERRA PARRA, Manuel; MAURA MIJARES, Rafael. 2006: Arte rupestre prehistórico en la Serranía de Ronda. Editorial La Serranía. Ronda.

CANTALEJO DUARTE, Pedro; MAURA, Rafael; ARANDA, Antonio; ESPEJO, María del Mar. 2007: Prehistoria en las cuevas del Cantal. Editorial La Serranía. RONDA.

CANTILLO DUARTE, Juan J.; VIJANDE VILA, Eduardo; CISCAR MALIA, Juan J.; TORRES ABRIL, Francisco; BEJARANO GUEIMÚNDEZ, Diego; CABRAL MESA, Antonio. 2014: "Aportación al conocimiento de la secuencia pleistocena del río Guadalete a partir de los resultados arqueológicos en la cantera la Isabelita (Arcos de la Frontera, Cádiz)". Almajar, Revista de Historia, Arqueología y Patrimonio de Villamartín, IV-V, pp. 17-35.

CARRIÓN, José S.; OCHANDO, Juan: FERNÁNDEZ, Santiago, BLASCO, Ruth; ROSELL, Jordi; MUNUERA, Manuel; AMORÓS, Gabriela; MARTÍN-LERMA, Ignacio; FINLAYSON, Stewart; GILES, Francisco; JENNINGS, Richard; FINLAYSON, Geraldine; GILES-PACHECO, Francisco; RODRÍGUEZ-VIDAL, Joaquín; FINLAYSON, Clive. 2018: "Last Neanderthals in the Warmest Refugium of Europe: Palynological Data from Vanguard Cave." Review of Palaeobotany and Palynology, 259, pp. 63-80.

CARRIÓN, José S.; FERNÁNDEZ, Santiago; JIMÉNEZ-ARENAS, Juan M.; MUNUERA, Manuel; OCHANDO, Juan; AMORÓS, Gabriela; PONCE DE LEON Marcia; ZOLLIKOFER, Cristopher; MARTÍN-LERMA, Ignacio; TORO-MOYANO, Isidro, HAJDAS, Irka; WALKER, Michael J. 2019: "The sequence at Carihuela Cave and its potential for research into Neanderthal ecology and the Mousterian in southern Spain". Quaternary Science Reviews, 217, pp. 
194-216 https://doi.org/10.1016/J.QUASCIREV.2019.04.012.

CASCALHEIRA, Joao, 2010: “Tecnología lítica solutrense do Abrigo de Vale Boi (Vila do Bispo)". Tecnologia Lítica Solutrense do Abrigo de Vale Boi (Vila do Bispo). Centro de Arqueologia da Universidade de Lisboa. Lisboa.

CASCALHEIRA, Joao; BICHO, Nuno; MARREIROS, Joao; PEREIRA, Telmo; ÉVORA, Marina, CORTÉS, Miguel; GIBAJA, Juan F; MANNE, Tiina; REGALA, Federico; GONÇALVES, Celia; MONTEIRO, Patricia. 2012: "Vale Boi (Algarve, Portugal) y el Solutrense en el suroeste de la península Ibérica". Espacio, Tiempo y Forma. Serie I, Prehistoria y Arqueología, t-5, pp. 455467. https://doi.org/10.5944/etf.

CASTAÑEDA FERNÁNDEZ, Vicente y HERRERO LAPAZ, Nuria. 1998: "Torre Almirante (Algeciras, Cádiz) Un nuevo asentamiento al aire libre de cazadores-recolectores especializados en el sur de la península Ibérica". Caetaria, Museo Municipal, 2, pp.11-24.

CASTAÑEDA FERNÁNDEZ, Vicente; PÉREZ RAMOS, Luis; TORRES ABRIL, Francisco; Costela Muñoz, Yolanda. 2020: "El sitio al aire libre con tecnología solutrense de la Fontanilla (Conil de la Frontera, Cádiz, España). Dataciones absolutas y estudio de los productos líticos a raíz de las últimas excavaciones". Lucentum, XXXIX, pp. 31-51. https://doi.org/10.14198/ LVCENTVM2020.39.02.

COLLADO GIRALDO, Hipólito; BEA, Manuel; RAMOS-MUÑOZ, José; CANTALEJO, Pedro; DOMÍNGUEZ BELLA, Salvador; BELLO, José R.; ANGÁS, Jorge; NIRANDA, Jorge; GRACIA PRIETO, Francisco J.; FERNÁNDEZ, Diego S.; ARANDA, Juan A.; LUQUE, Antonio J.; GARCÍA, José J.; AGUILAR, Juan C. 2019: "Un nuevo grupo de manos paleolíticas pintadas". Zephyrus, LXXXIII, pp. 15-38.

CORTÉS SÁNCHEZ, Miguel. 2002: “El Paleolítico Superior Final en el sur de la península Ibérica: los yacimientos de la provincia de Málaga". Mainake, 24, 279-300.

CORTÉS SÁNCHEZ, Miguel; MARREIROS, Joao; SIMÓN, María D.; GIBAJA, Juan F.; BICHO, Nuno. 2005: "Reevaluación del Gravetiense en el sur de Iberia”. En M. HERNÁNDEZ y J. A. SOLER (eds.): Actas del Congreso de Arte Rupestre en la España Mediterránea, pp. 17-43. Diputación Provincial de Alicante, Instituto Alicantino de Cultura Juan Gil-Albert, Caja de Ahorros del
Mediterráneo. Alicante.

CORTÉS SÁNCHEZ, Miguel. 2007: Cueva Bajondillo (Torremolinos, Málaga). Secuencia Cronocultural y Paleoambiental del Cuaternario Reciente en la Bahía de Málaga. Centro de Ediciones de la Diputación de Málaga, Servicio de Publicaciones. Málaga.

CORTÉS SÁNCHEZ, Miguel. 2007: "Las industrias líticas del Paleolítico medio y superior". En M. CORTÉS (ed.): Cueva de Bajondillo (Torre Molinos). Secuencia cronocultural y paleoambiental del Cuaternario reciente en la Bahía de Málaga, pp. 171-446. Servicio de Publicaciones Centro de ediciones de la Diputación de Málaga, Málaga.

CORTÉS SÁNCHEZ, Miguel; FERRER PALMA, José E.; MARQUÉS MERELO, Ignacio; BALDOMERO NAVARRO, Ana; SIMÓN VALLEJO, María D. 2007: "Apuntes cronológicos, paleoambientales y culturales al tránsito Paleolítico Medio-Superior en cueva Bajondillo (Torremolinos, Málaga)". Mainake, XXIX, pp. 493-512.

CORTÉS SÁNCHEZ, Miguel; JIMÉNEZ ESPEJO, Francisco J.; SIMÓN VALLEJO, María D.; LÓPEZ SÁEZ, José A.; RIQUELME CANTAL, José A.; FERNÁNDEZ DOMÍNGUEZ, Eva; MARTÍNEZ RUIZ, Francisca; PRATS MIRAVITLLAS, Eva; ARROYO, Eduardo; PÉREZ-PÉREZ, Alejandro; TURBÓN BORREGA, Daniel; LÓPEZ MERINO, Lourdes; PÉREZ DÍAZ, Sebastián. 2008: "La investigación sobre El Pirulejo. Una aproximación interdisciplinar". Antiqvitas, 20, pp. 213221.

CORTÉS SÁNCHEZ, Miguel; SIMÓN-VALLEJO, María D.; MORALES-MUÑIZ, Arturo; LOZANO FRANCISCO, María del C.; VERA PELÁEZ, José L.; ODRIOZOLA LLORET, Carlos. 2016: "La caverna iluminada: una singular lámpara Gravetiense arroja luz sobre el arte parietal de la cueva de La Pileta (Benaoján, Málaga)". Trabajos de Prehistoria, 73(1), pp. 115-127

CORTÉS SÁNCHEZ, Miguel, JIMÉNEZ-ESPEJO, Francisco J.; SIMÓN-VALLEJO, María D.; STRINGER, Chris; LOZANO FRANCISCO, María del C.; GARCÍA-ALIX, Antonio; VERA PELÁEZ, José; ODRIOZOLA, Carlos P.; RIQUELME-CANTAL, José A.; PARRILLA GIRÁLDEZ, Rubén; MAESTRO GONZÁLEZ, Adolfo; OHKOUCHI, Naohiko; MORALES-MUÑIZ, Arturo. 2019: "An early Aurignacian arrival in southwestern Europe". Nature Ecology \& Evolution, 3(2), pp. 207-212. https://doi.org/10.1038/s41559- 
018-0753-6.

DE LA PEÑA ALONSO, Paloma. 2009: "Revisión crítica de los conjuntos líticos gravetienses y su contexto arqueológico en la península Ibérica". Complutum, 20(1), pp. 29-53.

DE LA PEÑA ALONSO, Paloma. 2011: "Sobre la identificación macroscópica de las piezas astilladas: Propuesta experimental". Trabajos de Prehistoria, 68(1), pp. 79-98. https://doi. org/10.3989/tp.2011.11060.

DE LA PEÑA ALONSO, Paloma. 2013: "The transition in southern Iberia: insights from paleoclimatology and the Early Upper Palaeolithic". Proceedings of the National Academy of Sciences of the United States of America, 110(23), E2086. https://doi.org/10.1073/ pnas.1303596110.

DE LA PEÑA ALONSO, Paloma. 2013: "The beginning of the Upper Palaeolithic in the Baetic Mountain area (Spain)". Quaternary International, 318, pp. 69-89. https://doi.org/10.1016/j.quaint.2013.08.008.

DE LA PEÑA ALONSO, Paloma. 2019: “Dating on its own cannot resolve hominin occupation patterns". Nature Ecology \& Evolution, 1. https:// doi.org/10.1038/s41559-019-0886-2.

FERNÁNDEZ, Santiago; FUENTES, Naomi; CARRIÓN, José S., GONZÁLEZ-SAMPÉRIZ, Penélope, MONTOYA, Encarna, GIL-ROMERA, Graciela, VEGA-TOSCANO, L. Gerardo, RIQUELME, José A. 2007: "The Holocene and Upper Pleistocene pollen sequence of Carihuela Cave, southern Spain". Geobios, 40(1), pp. 75-90. https://doi.org/10.1016/J.GEOBIOS.2006.01.004.

FERNÁNDEZ SÁNCHEZ, Diego S.; MENDOZA LÓPEZ, Diego; GILES PACHECO, Francisco; GUTIÉRREZ LÓPEZ, José Mạ 2017: "La Cueva VR-15 (Villaluenga del Rosario, Cádiz) y las manifestaciones gráficas del sur peninsular. Un modelo explicativo de los modos de vida y producción de las bandas cazadoras recolectoras del Paleolítico superior". En F. SILES, J. RAMOS, V. MARTÍNEZ, J. M. GUTIÉRREZ y J. A. MARTÍN (eds.): Las ocupaciones por sociedades prehistóricas, protohistóricas y de la antigüedad en la Serranía de Ronda y Béticas Occidentales, Actas del I Congreso Internacional de Historia de la Serranía de Ronda, pp. 217-246. Editorial La Serranía S. L. Instituto de Estudios de Ronda y La Serranía (IERS). Ronda.

FERNÁNDEZ SÁNCHEZ, Diego S.; COLLADO GIRAL-
DO, Hipólito; RAMOS MUÑOZ, José; LUQUE, Antonio; DOMÍNGUEZ BELLA, Salvador; BEA, Manuel; BELLO, José R.; ANGÁS PAJAS, Jorge; MIRANDA OLIVÁN, Jorge; GARCÍA ARRANZ, José J.; AGUILAR, Juan C.; MIRA, Hugo; ESCALONA, Salvador. 2019: "Nuevos motivos de manos aerografiadas paleolíticas en Cueva de las Estrellas (Castellar de la Frontera, Cádiz) y Cueva de las Palomas IV (Tarifa, Cádiz)”. En G. GARCÍA y V. BARCIELA (coords.): Sociedades prehistóricas y manifestaciones artísticas: Imágenes, nuevas propuestas e interpretaciones, Alicante: Instituto Universitario de Investigación en Arqueología y Patrimonio Histórico (INAPH), pp. 49-54. Universidad de Alicante. Alicante.

FERRER PALMA, José E.; MARQUÉS MERELO, Ignacio; CORTÉS SÁNCHEZ, Miguel; RAMOS FERNÁNDEZ, Julián; BALDOMERO NAVARRO, Ana. 2006: "Excavaciones en Cueva del Hoyo de la Mina (Málaga, Andalucía, España): Contrastación de una secuencia arqueológica clásica para el estudio del Tardiglaciar-Holoceno antiguo en el sur de la península Ibérica”. En J. L. SANCHIDRIÁN, A. M. MÁRQUEZ y J. M. FULLOLA Y PERICOT (eds.): La cuenca mediterránea durante el Paleolítico Superior: 38.000-10.000 años, pp. 125-145. Fundación Cueva de Nerja. Málaga.

FINLAYSON, Clive; GILES PACHECO, Francisco; RODRÍGUEZ VIDAL, Joaquín; FA, Darren; GUTIERREZ LÓPEZ, José M.; SANTIAGO PÉREZ, Antonio; FINLAYSON, Geraldine; ALLUE, Ethel; BAENA PREYSLER, Javier; CÁCERES, Isabel; CARRIÓN, José S.; FERNÁNDEZ JALVO, Yolanda; GLEED-OWEN, Chris P.; JIMENEZ ESPEJO, Francisco J.; LÓPEZ, Pilar; LÓPEZ SÁEZ, José A.; RIQUELME CANTAL, José A.; SÁNCHEZ MARCO, Antonio; GILES GUZMAN, Francisco; BROWN, Kimberly; FUENTES, Naomi; VALARINO, Claire A.; VILLALPANDO, Antonio; STRINGER, Chris. B.; MARTINEZ RUIZ, Francisca; TATSUHIKO, Sakamoto. 2006: "Late survival of Neanderthals at the southernmost extreme of Europe". Nature, 443, pp. 850-853. doi:10.1038/nature05195.

FINLAYSON, Clive; FA, Darren; JIMÉNEZ ESPEJO, Francisco; CARRIÓN, José S.; FINLAYSON, Geraldine; GILES PACHECO, Francisco; RODRÍGUEZ VIDAL, Joaquín; STRINGER, Chris B.; MARTÍNEZ RUIZ, Francisca. 2008: “Gorham's Cave, Gibraltar. The persistence of a Neander- 
thal population". Quaternary International, 181(1), pp. 64-71. https://doi.org/10.1016/j. quaint.2007.11.016.

FORTEA PÉREZ, F. Javier; JORDÁ, Francisco. 1976: "La Cueva de Les Malladetes y los problemas del Paleolítico superior del Mediterráneo español". Zephyrus, XXVI-XXVII, pp. 129-166.

FORTEA PÉREZ, F. Javier. 1978: "Arte paleolítico del Mediterráneo español”. Trabajos de Prehistoria, 35, pp. 99-149.

FULLOLA, Josep M. 1976: "Revisión de la industria lítica de los niveles solutrenses de la Cueva del Parpalló". Pyrenae, 12. pp. 35-72.

FULLOLA, Josep M. 1978: "El Solutréo-gravetiense o Parpallense. Industria mediterránea". Zephyrus, XXVIII-XXIX, pp. 113-123.

FULLOLA Josep M.; VILLAVERDE Valentín; SANCHIDRIÁN José. L.; AURA Joan. E.; FORTEA, F. Javier; SOLER, Narcís. 2005: "El Paleolítico Superior Mediterráneo Ibérico". En J. L. SANCHIDRIÁN, A. M. MÁRQUEZ y J. M. FULLOLA (eds.): IV Simposio de Prehistoria Cueva de Nerja. La Cuenca Mediterránea durante el Paleolítico Superior, 38.000-10.000 años, pp. 192213. Fundación Cueva de Nerja. Málaga.

GARCÍA-FRANCO, M. Alejandro: MORGADO, Antonio. 2016: "Approach to the Blade Technology Analysis of the Upper Palaeolithic Site of "Tajos de Marchales" (Granada, Spain)". Journal of Lithic Studies, 3(2). https://doi.org/10.2218/ jls.v3i2.1883.

GARCÍA-FRANCO, M. Alejandro; MORGADO, Antonio. 2018: "Análisis de los métodos de talla de núcleos del Tajo de Marchales (Granada). Un yacimiento del Magdaleniense Mediterráneo." Cuadernos de Prehistoria y Arqueología de La Universidad de Granada, 28, pp. 213-231. https://doi.org/10.30827/cpag.v28i0.8483.

GAVILÁN, Beatriz; FERNÁNDEZ CARO, José Juan; FERNÁNDEZ GRAHAM, Miguel Ángel. 2020: "Open air Upper Paleolithic Site "Campiña": Los Álamos (Sevilla, Spain)". En I. SCHMIDT, J. CASCALHEIRA, N. BICHO, y G.-C. WENIGER (eds.): Human Adaptations to the Last Glacial Maximum. The Solutrean and its Neighbors. pp. 271-282. Cambridge Scholar Pubishing. Cambridge.

GILES GUZMÁN, Francisco J.; GILES PACHECO, Francisco; MARÍA GUTIÉRREZ LÓPEZ, José; JENNINGS, Richard; GIBAJA BAO, Juan F.; CLEMENTE CONTE, Ignacio; DOYAGUE REINOSO, Ana. 2017: "El Paleolítico superior de la Cueva de Higueral de Valleja (Arcos De La Frontera, Cádiz). Caracterización de los tecnocomplejos de los niveles III y IV". En F. SILES, J. RAMOS, V. MARTÍNEZ; J. M. GUTIÉRREZ y J. A. MARTÍN (eds.): Las ocupaciones por sociedades prehistóricas, protohistóricas y de la antigüedad en la Serranía de Ronda y Béticas Occidentales, Actas del I Congreso Internacional de Historia de la Serranía de Ronda, pp. 217-246. Editorial La Serranía S. L. - Instituto de Estudios de Ronda y La Serranía (IERS). Ronda.

GILES PACHECO, Francisco; SANTIAGO, Antonio; GUTIÉRREZ, José M.; MATA, Esperanza; AGUILERA, Luis. 1991: "Prospecciones Arqueológicas Superficiales en la cuenca del río Guada-

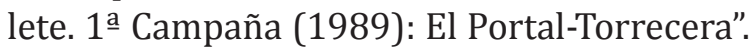
Anuario Arqueológico de Andalucía. 1989. II Actividades Sistemáticas. Informes y Memorias. Cádiz, pp. 26-34. Consejería de Cultura de la Junta de Andalucía. Dirección General de Bienes Culturales. Sevilla.

GILES PACHECO, Francisco; MATA ALMONTE, Esperanza; GUTIÉRREZ LÓPEZ, José M.; SANTIAGO PÉREZ, Antonio; AGUILERA RODRÍGUEZ, Luis: RODRIGUEZ VIDAL, Joaquín; RUIZ BUSTOS, Antonio. 1992: "Secuencia fluvial y paleolítica del rio Guadalete (Cádiz). 2 ${ }^{\underline{a}}$ campaña Torrecera - Junta de los Ríos, 1990". Anuario Arqueológico de Andalucía 1992. Actividades Sistemáticas. Informes y Memorias. Cádiz, pp. 28-34. Consejería de Cultura y Medio Ambiente de la Junta de Andalucía. Dirección General de Bienes Culturales. Sevilla.

GILES PACHECO, Francisco; MATA ALMONTE, Esperanza; GUTIÉRREZ LÓPEZ, José M.; SANTIAGO PÉREZ, Antonio; AGUILERA RODRÍGUEZ, Luis. 1993: "Secuencia fluvial y paleolítica del rio Guadalete (Cádiz). 3a Campaña: Junta de los Ríos - Arcos De La Frontera, 1991". Anuario Arqueológico de Andalucía 1991. Tomo II, pp. 75-82. Consejería de Cultura y Medio Ambiente de la Junta de Andalucía. Dirección General de Bienes Culturales. Sevilla.

GILES PACHECO, Francisco; GUTIÉRREZ, José M.; MATA, Esperanza; SANTIAGO, Antonio; GRACIA, Francisco J. 1995: "Secuencia fluvial y paleolítica del río Guadalete. 4⿳亠丷a Campaña: Prospecciones arqueológicas superficiales en la Depresión de Arcos de la Frontera (Cádiz)". Actividades Sistemáticas. Informes y Memorias, pp. 63-70. Consejería de Cultura de la Junta de Andalucía, Dirección General de Bienes Cultu- 
rales. Sevilla.

GILES PACHECO, Francisco; SANTIAGO PÉREZ, Antonio; GUTIÉRREZ LÓPEZ, José M.; MATA ALMONTE, Esperanza. 1997: "Las comunidades del Paleolítico Superior en el extremo sur de Andalucía Occidental. Estado de la cuestión". En R. BALBÍN y P. BUENO (eds.): Paleolítico y Epipaleolítico. Tomo I. II Congreso de Arqueología Peninsular, pp. 383-403. Fundación Rei Afonso Henriques. Zamora.

GILES PACHECO, Francisco; GUTIÉRREZ LÓPEZ, José M.; SANTIAGO PÉREZ, Antonio; MATA ALMONTE, Esperanza. 1998: "Avance al estudio sobre el poblamiento del Paleolítico Superior en la cuenca medio y alta del río Guadalete (Cádiz)". J. L. SANCHIDRIÁN \& M. D. SIMÓN (Eds.), Las Culturas del Pleistoceno Superior en Andalucía. I Simposio de Prehistoria Cueva de Nerja. Homenaje al Profesor Francisco Jordá Cerdá, pp. 11-14. Patronato de Nerja. Nerja.

GILES PACHECO, Francisco; SANTIAGO, Antonio; MATA, Esperanza; AGUILERA, Luis; GUTIÉRREZ, José Ma 1999. "El Paleolítico de la cuenca media del Guadalete en el tramo Cádiz-Sevilla". Mauror, 7, pp. 55-69.

GILES PACHECO, Francisco; SANTIAGO PÉREZ, Antonio; GUTIÉRREZ LÓPEZ, José M.; MATA ALMONTE, Esperanza; AGUILERA RODRÍGUEZ, Luis. 2000: "New contributions to the Upper Palaeolithic sequence of Gibraltar and its importance in the south-western Palaeolithic framework of the Iberian Peninsula". En C. FINLAYSON, G. FINLAYSON y D. FA (eds.): Gibraltar during the Quaternary, pp. 159-168. Gibraltar Goverment Heritage Division. Gibraltar.

GILES PACHECO, Francisco: SANTIAGO, Antonio; AGUILERA, Luis; GUTIÉRREZ, Jose María; FINLAYSON, Clive (2003). "Paleolítico Inferior y Medio en la sierra de Cádiz. Evidencias de grupos de cazadores-recolectores del Pleistoceno medio y superior". Almajar 1, pp. 8-35.

GILES PACHECO, Francisco; GILES GUZMÁN, Francisco; GUTIÉRREZ LÓPEZ, José M.; JENNINGS, Richard; GIBAJA, Juan F.; CLEMENTE-CONTE, Ignacio; BERNAL, Marco A. 2012: "La sucesión Solutrense-Gravetiense de la cueva de Higueral de Valleja (Cádiz, Spain)". Congreso Internacional el Solutrense, Vélez Blanco, pp. 41-42. Almería .

GILES PACHECO, Francisco; GILES GUZMÁN, Francisco J.; GUTIÉRREZ LÓPEZ, José M.; SAN-
TIAGO PÉREZ, Antonio; FINLAYSON, Clive; RODRÍGUEZ VIDAL, Joaquín; FINLAYSON, Geraldine; FA, Darren A. 2012: "The tools of the last Neanderthals: Morphotechnical characterisation of the lithic industry at level IV of Gorham's Cave, Gibraltar". Quaternary International, 247, pp. 151-161. https://doi.org/10.1016/J.QUAINT.2011.02.026.

GILES PACHECO, Francisco, GUTIERREZ LOPEZ, José M.; CARRASCAL, José M; GILES GUZMÁN, Francisco J.; DOYAGUE REINOSO, Ana M.; DOMÍNGUEZ BELLA, Salvador. 2016: "Un ornamento singular atribuido a cazadores recolectores solutrenses en el yacimiento al aire libre de La Toleta (Puerto Serrano, Cádiz)". ARPI, 4, pp. 49-63.

GILES PACHECO, Francisco; GUTIÉRREZ LÓPEZ, José M.; CARRASCAL, José M.; GILES GUZMAN, Francisco; DOYAGUE REINOSO, Ana M.; DOMÍNGUEZ-BELLA, Salvador. 2017: "Nuevo yacimiento al aire libre de cazadores recolectores solutrenses en el alto Guadalete: La Toleta, Puerto Serrano, Cádiz-España". En J. RAMOS MUÑOZ, F. SILES, J. M. GUTIÉRREZ, V. MARTÍNEZ y J. A. MARTÍN (eds.): Las ocupaciones por sociedades prehistóricas, protohistóricas y de la antigüedad en la Serranía de Ronda y Béticas Occidentales, pp. 271-294. Instituto de Estudios de Ronda y la Serranía. Editorial La Serranía. Ronda.

GONZÁLEZ-SAMPÉRIZ, Penélope; LEROY, Suzanne A. G.; CARRICN, José S.; FERNÁNDEZ, Santiago; GARCÍA-ANTON, Mercedes; GIL-GARCÍA, María J.; UZQUIANO, Paloma; VALERO-GARCÉS, Blas, FIGUEIRAL, Isabel. 2010: "Steppes, savannahs, forests and phytodiversity reservoirs during the Pleistocene in the Iberian Peninsula". Review of Palaeobotany and Palynology, 162(3), pp. 427-457. https://doi.org/10.1016/j.revpalbo.2010.03.009.

GUTIÉRREZ LÓPEZ, José M.; SANTIAGO PÉREZ, Antonio; GILES PACHECO, Francisco; GRACIA PRIETO, F. Javier; MATA ALMONTE, Esperanza. 1994: "Areas de transformación de recursos líticos en glacis de la depresión de Arcos de la Frontera (Cádiz)". En J. F. JORDÁ (ed.): Actas de la 2a Reunión Nacional de Geoarqueología (Madrid, 1992), pp. 305-316. Instituto Tecnológico Geominero de España, AEQUA. Madrid.

GUTIÉRREZ LÓPEZ, José M.; GILES PACHECO, Francisco; GILES GUZMÁN, Francisco J.; FIN- 
LAYSON, Clive; BERNAL GÓMEZ, Marco A.; RODRÍGUEZ VIDAL, Joaquín; FA, Darren. 2012: "La ocupación Solutrense del tramo interno de Gorham's Cave. Gibraltar". En B. Avezuela y J. Jordá (eds.): Congreso Internacional el Solutrense, 25-28 de junio de 2012. Libro de resúmenes , pp. 59-60. Almería.

HAWS, Jonathan A.; BENEDETTI, Michael M.; TALAMO, Sahra; BICHO, Nuno; CASCALHEIRA, João; ELLIS, M. Grace; CARVALHO, Milena M.; FRIEDL, Lukas; PEREIRA, Telmo; ZINSIOUS, Brandon K. 2020: "The Early Aurignacian Dispersal of Modern Humans into Westernmost Eurasia." Proceedings of the National Academy of Sciences, 117, 41 (October 13, 2020): 25414-22. https://doi.org/10.1073/ pnas. 2016062117.

HOFFMANN, Dirk L.; STANDISH, Cristopher D.; GARCÍA-DIEZ, Marco; PETTITT, Paul B.; MILTON, James A.; ZILHÃO, J João; ALCOLEA GONZÁLEZ, Javier J.; CANTALEJO DUARTE, Pedro; COLLADO, Hipólito; BALBÍN, Rodrigo de; LORBLANCHET, Michael; RAMOS, José; WENIGUER, Gerd Ch.; PIKE, Alistair W. G. 2018: "U-Th dating of carbonate crusts reveals Neandertal origin of Iberian cave art". Science, 359(6378). https://doi.org/10.1126/science. aap7778.

JENNINGS, Richard; FINLAYSON, Clive; FA, Darren; FINLAYSON, Geraldine. 2011. "Southern Iberia as a refuge for the last Neanderthal populations". Journal of Biogeography, 38(10), pp. 1873-1885.

JENNINGS, Richard P.; GILES PACHECO, Francisco; BARTON, R. Nicholas E.; COLLCUT, Simon N.; GALE, Rowena; GLEED-OWEN, Chris P.; GUTIÉRREZ LÓPEZ, José M.; HIGHAM, Tom F. G.; PARKER, Adrian; PRICE, Catherine; RHODES, Edward; SANTIAGO PÉREZ, Antonio; SCHWNINGER, Jean-Luc; TURNER, Elaine. 2009: "New dates and palaeoenvironmental evidence for the Middle to Upper palaeolithic occupation of Higueral de Valleja cave, southern Spain", Quaternary Sciencies Reviews, 28(910), pp. 830-839.

JORDÁ CERDÁ, Francisco. 1955: El Solutrense en España y sus problemas. Diputación Provincial de Asturias. Oviedo.

JORDÁ PARDO, Jesús F.; AURA TORTOSA, Juan E.; AVEZUELÑA ARISTU, Bárbara; PÉREZ RIPOLL, Sergio, TIFFAGOM, Marc. 2008: "El Gravetiense de la Cueva de Nerja". Le Gravettien et
Ses Descendances, pp. 27-34. Perpignan.

MARTÍNEZ ANDREU, Miguel. 1989: El Magdaleniense superior en la costa de Murcia. Colección Documentos, núm. 2. Editora Regional de Murcia. Murcia.

MARTÍNEZ ANDREU, Miguel. 2007: "Nuevas aportaciones al estudio del Solutrense murciano". Veleia. Revista de Prehistoria, Historia Antigua, Arqueología y Filología Clásicas, 24-25, pp. 469-482.

MARTÍN-LERMA, Ignacio; ROMAN, Didac ; SANCHEZ, Noelia. 2020 : "Las ocupaciones paleolíticas de la Cueva del Arco (Cieza, Murcia) ". En XXV Jornadas de Patrimonio Cultural Región de Murcia, pp. 123-130. Comunidad Autónoma de la Región de Murcia, Consejería de Educación y Cultura Dirección General de Bienes Culturales. Murcia.

MAS CORNELLÀ, Martí; RIPOLL LÓPEZ, Sergio; MARTOS ROMERO, Juan A.; PANIAGUA PÉREZ, José P.; LÓPEZ MORENO DE REDROJO, José R.; BERGMANN, Lothar. 1995: "Estudio preliminar de los grabados rupestres de la Cueva del Moro (Tarifa, Cádiz) y el arte paleolítico del Campo de Gibraltar". Trabajos de Prehistoria, 52(2), pp. 61-81. https://doi.org/10.3989/ tp.1995.v52.i2.418.

MAS CORNELLÁ, Martí; RIPOLL, Sergio; TORRA, Guadalupe; JORDÁ, J. Francisco; GAVILÁN, Beatriz, VERA, Carlos. 1996: "El poblamiento prehistórico del campo de Gibraltar". Espacio, Tiempo y Forma. Serie I, Prehistoria y Arqueología, 9, pp. 207-224. https://doi.org/10.5944/ etfi.9.1996.4634.

MEDINA ALCAIDE, M. Ángeles; CABALÍN, Luisa M.; LASERNA, Javier; SANCHIDRIÁN, José L.; TORRES, Antonio J.; INTXAURBE, Iñaki; COSANO, Sonia; ROMERO, Antonio. 2019: "Multianalytical and multiproxy approach to the characterization of a Palaeolithic lamp. An example in Nerja cave (Southern Iberian Peninsula)". Journal of Archaeological Science: Reports, 28, 102021. https://doi.org/10.1016/j.jasrep.2019.102021.

MEDINA ALCAIDE, M. Ángeles; TORRES RIESGO, Antonio J.; INTXUAURBE ALBERDI, Iñaki; SALAZAR CAÑETE, Sergio; ARRIOLABENGOA ZUBIZARRETA, Martín; COSANO PÉREZ, Sonia; GRANADOS TRUJILLO, Belén; GOMAR BAREA, Ana M.; RUIZ-MÁRQUEZ, Rosa M.; MESA ALGAR, Loli; NAVARRO YÉBENES, Juan; RAMÍREZ ORTIZ, Agustín; RODRÍGUEZ CASTRO, 
Eva; RUIZ TRUJILLO, Antonio; LÓPEZ RODRÍGUEZ, Antonio; SANTIAGO PÉREZ, Antonio; JIMENA FERNÁNDEZ, David; GARATE MAIDAGAN, Diego; RIVERO VILA, Olivia; SANCHIDRÍÁN TORTI, José L.; GIEX. 2019: “Las cuevas con arte paleolítico del Cerro de Las Motillas (Jerez de la Frontera, Cádiz - Cortes de la Frontera, Málaga)". En G. GARCÍA y V. BARCIELA (eds.): Sociedades prehistóricas y manifestaciones artísticas. Imágenes, nuevas propuestas $e$ interpretaciones, pp. 55-61. Publicaciones INAPH, Colección Petrarcos. Alicante.

MUÑOZ IBÁÑEZ, Francisco J. 2000: Las puntas ligeras de proyectil del solutrense extracantábrico: análisis tecnomorfológico e implicaciones funcionales. Universidad Nacional de Educación a Distancia. Madrid.

OBERMAIER, Hugo. 1985: El Hombre Fósil. Madrid, Istmo [Reproducción facsímile de la edición de 1925]. Museo Nacional de Ciencias Naturales. Madrid.

OTTE, Marcel, 1997: « Contacts trans-méditarrenéens au Paleélithique ». En J. M. FULLOLA y N. SOLER (eds.): El mon mediterrani deprés del pleniglaciar (18.000-12.000 BP), pp. 29-39. U. I. S. P. P., Comisión VIII, Serie Monográfica, 17.

PEARCE, David G.; BONNEAU, Adelphine. 2018: "Trouble on the dating scene". Nature Ecology and Evolution, 2, pp. 925-926. https://doi. org/10.1038/s41559-018-0540-4.

PERICOT, Luis. 1942: La cueva del Parpalló, Gandía, Valencia. CSIC, Instituto Diego Velázquez. Madrid.

PETTIT, Paul B.; BAILEY, Richard M. 2000. "AMS radiocarbon and luminescence dating of Gorham's and Vanguard Caves, Gibraltar, and implications for the Middle to Upper Palaeolithic transition in Iberia". En C. B. STRINGER, R. N. E. BARTON y C. FINLAYSON (eds.): Neanderthals on the Edge, pp. 155-162. Oxbow Books. Oxford.

PIKE, A. W. G.; HOFFMANN, Dirk L.; GARCÍA-DIEZ, Marcos; PETTITT, Paul; ALCOLEA, Javier; DE BALBÍN, Rodrigo; GONZÁLEZ SAINZ, C.; DE LAS HERAS, Carmen; LASHERAS, José A.; MONTES, Ramón; ZILHÃO, João. 2012: “U-series dating of paleolithic art in 11 caves in Spain". Science, 336 (6087), pp. 1409-1413. https://doi.org/10.1126/science.1219957.

PONS-BRANCHU, Edwige; SANCHIDRIÁN, José L.; FONTUGNE, Michael; MEDINA-ALCAIDE, María Á.; QUILES, Anita; THIL, Francois, VALLA-
DAS, Helene. 2020: "U-series dating at Nerja cave reveal open system. Questioning the Neanderthal origin of Spanish rock art". Journal of Archaeological Science, 117, 105120. https://doi.org/10.1016/j.jas.2020.105120.

RAMOS FERNÁNDEZ, Julián; DURÁN VALSERO, Juan J. 1998: "El Solutrense de la Araña (Málaga)". En J.L. SANCHIDRIÁN y M.D. SIMÓN (eds.): Las culturas del Pleistoceno Superior en Andalucía, pp. 63-75. Patronato de la Cueva de Nerja. Málaga.

RAMOS FERNÁNDEZ, Julián; CORTÉS SÁNCHEZ, Miguel; AGUILERA LÓPEZ, Raul; LOZANO FRANCISCO, María del C.; VERA PELÁEZ, José L.; SIMÓN VALLEJO, María D. 2006: "El Magdaleniense y Epipaleolítico del Abrigo 6 del Complejo del Humo (La Araña, Málaga)". En J.L. SANCHIDRIÁN, A.M. MÁRQUEZ y J.M. FULLOLA (eds.): La Cuenca Mediterránea durante el Paleolítico Superior 38000-10000 años, pp. 326-341. IV Simposio de Prehistoria Cueva de Nerja. Reunión de la VIII Comisión del Paleolítico Superior UISP, Nerja 2004, pp. 326-341. Fundación Cueva de Nerja. Málaga.

RAMOS MUÑOZ, José; CASTAÑEDA, Vicente; PÉREZ, Manuela; LAZARICH, María; MONTAÑÉS, Manuel; ARROQUIA, María I.; BLANES, Carmen; MARTÍNEZ, Cristina; DOMÍNGUEZ, Salvador; GRACÍA, Javier; MORATA, Diego; PÉREZ, Luis; GÓMEZ, María Isabel; HERRERO, Nuria; REINA, Asunción; CANTALEJO, Pedro; BRITO, María del M.; GUZMÁN, Juan C.; CALDERÓN, Diego; LOZANO, José M.; SORIANO, Magdalena. 1995: El Paleolítico Superior Final del río Palmones (Algeciras, Cádiz). Un ejemplo de la tecnología de las comunidades especializadas de cazadores-recolectores. Instituto de Estudios Campogibraltareños. Algeciras.

RAMOS MUÑOZ, José; CANTALEJO DUARTE, Pedro; ESPEJO HERRERÍAS, María del M. 1999: "El arte de los cazadores-recolectores como forma de expresión de los modos de vida. Historiografía reciente y crítica a las posiciones eclécticas de la posmodernidad". Revista Atlántica-Mediterránea de Prehistoria y Arqueología Social, 2, pp. 151-177.

RAMOS MUÑOZ, José; CANTALEJO DUARTE, Pedro; ESPEJO HERRERÍAS, María Dedl M.; MAURA MIJARES, Rafael; MEDIANERO SOTO, Javier. 2002: "La imagen de la mujer en las manifestaciones artísticas de la cueva de Ardales (Ardales, Málaga). Un enfoque desde la relación 
dialéctica producción y reproducción social". Revista Atlántica-Mediterránea de Prehistoria y Arqueología Social, 5, pp 87-124. https:// doi.org/10.25267/Rev atl-mediterr prehist arqueol soc.2002.v5.03.

RAMOS MUÑOZ, José; ALMISAS, Sergio; DOYAGUE, Ana; DOMINGUEZ BELLA, Salvador; BARRENA, Antonio; PÉREZ, Antonio; TOLEDO, Jesus; CANTILLO, Juan J.; MARTÍNEZ, Raquel; FERNÁNDEZ, Diego. 2014: "La Fontanilla (Conil de la Frontera, Cádiz). Nuevos productos arqueológicos vinculados a la ocupación del yacimiento por sociedades cazadoras-recolectoras con tecnología de Modo 4". Almajar. Revista del Museo de Villamartín, 4-5, pp. 18-58.

RAMOS MUÑOZ, José; WENIGER, Gerd C.; CANTALEJO, Pedro, BOLÍN, Viviane; KEHL, Martin; ESPEJO, María del M.; TAFELMAIER, Yvonne; PASTOORS, Andreas; DOMÍNGUEZ-BELLA, Salvador; CABELLO, Lidia; OTTO, Taylor; FERNÁNDEZ-SÁNCHEZ, Diego; MORENO-MÁRQUEZ, Adolfo; ROTGANGER, Miriam; VIJANDE, Eduardo; BECERRA, Serafín, NIELSEN, Trine K.; BARRENA, Antonio; ALMISAS, Sergio; CANTILLO, Juan J.; RIQUELEME, José A., BELTRÁN, Alejandro; UZQUIANO, Paloma; RAMOS, Pablo; BAILÓN, Salvador, ROFÉS, Juan, SÁNCHEZ-MARCO, Antonio. 2019: "Excavations in Solutrean Levels of Ardales Cave (Málaga, Spain)". En I. SCHMIDT, J. CASCALHEIRA, N. BICHO, y G.-C. WENIGER (eds.): Human Adaptations to the Last Glacial Maximum. The Solutrean and its Neighbors, pp. 171-187. Cambridge Scholar Pubishing. Cambridge.

RIQUELME CANTAL, José Antonio; CALLE ROMÁN, Lydia; ARANDA SÁNCHEZ, Victoria; CÁNOVAS CALLE, Isabel; PARRILLA GIRÁLDEZ, Rubén; SIMÓN VALLEJO, María D.; CORTÉS SÁNCHEZ, Miguel. 2020. "The Solutrean in Las Ventanas Cave (Granada, Spain)" En I. SCHMIDT, J. CASCALHEIRA, N. BICHO y G. C. WENIGER (eds.): Human Adaptations to the Last Glacial Maximum. The Solutrean and its Neighbors, pp. 255270. Cambridge Scholar Pubishing. Cambridge. RIPOLL LÓPEZ, Sergio. 1988: La Cueva de Ambrosio y su posición cronoestratigráfica en el Mediterráneo Occidental. British Archaeological Reports, 462, Archaeopress. Oxford.

RIPOLL LÓPEZ, Sergio; MAS CORNÉLLA, Martí; JORDÁ PARDO, Jesús F. 1998: "Las cuevas de Levante (Benalup, Cadiz): un yacimiento al aire libre del Paleolítico Superior en Anda- lucía suroccidental". Trabajos de Prehistoria, 55(2), pp. 21-33. https://doi.org/10.3989/ tp.1998.v55.i2.301.

RIPOLL LÓPEZ, Sergio; MUÑOZ IBÁÑEZ, Francisco J.; LATOVA FERNÁNDEZ-LUNA, José. 2006: "Nuevos datos para el arte rupestre paleolítico de la Cueva de Ambrosio (Vélez-Blanco, Almería)". En J. MARTÍNEZ GARCÍA y M. S. HERNÁNDEZ PÉREZ (eds.): Actas del Congreso de Arte Rupestre Esquemático en la península Ibérica: Comarca de los Vélez, 5-7 de Mayo 2004, pp. 573-588. Vélez-Blanco.

RIPOLL LÓPEZ, Sergio; JORDÁ PARDO, Jesús F.; MUÑOZ IBÁÑEZ, Francisco J.; YRAVEDRA, José; AVEZUELA ARISTU, Bárbara; MARTÍN LERMA, Ignacio. 2013: "El Solutrense de la Cueva de Ambrosio (Vélez-Blanco, Almeria, España): nuevos datos cronoestratigráficos y arqueológicos". En Le Solutréen 40 ans après Smith'66, pp. 75-86. Fédération pour l'édition de la Revue Archéologique du Centre de la France, (Supplément à la Revue Archéologique du Centre de la France, 47). Tours.

ROMAN MONROIG, Didac; ZILHÃO, Joao; MARTÍN-LERMA, Ignacio; VILLAVERDE, Valentín. 2013: "La ocupación epimagdaleniense del abrigo de la Finca de Doña Martina (Mula, Murcia)". Dídac, 5 pp. 167-178.

SÁNCHEZ-TARIFA, Carlos. 2004: "Las industrias líticas de la cueva de las Ventanas de Píñar (Granada) desde el Paleolítico Superior a la Edad del Cobre”. @rqueología y Territorio, 1, pp. 1-13.

SANCHIDRIÁN TORTI, José L. 1982: "La cueva del Morrón (Jimena, Jaén)". Zephyrus, XXXIVXXXV (0), pp. 5-11.

SANCHIDRIÁN TORTI, José L. 1981: Cueva Navarro (Cala del Moral, Málaga). Corpus Artis Rupestris I. Palaeolithica Ars, vol. 1. Universidad de Salamanca. Salamanca.

SANCHIDRIÁN TORTI, José L. 1994: Arte Rupestre de la Cueva de Nerja. Trabajos sobre la Cueva de Nerja, no 4 . Patronato de la Cueva de Nerja. Málaga.

SANCHIDRIÁN TORTI, José L; MÁRQUEZ, Ana M., VALLADAS, Helène; TISNERAT, Nadine. 2001; "Dates directes pour l'art rupestre d'Andalousie (Espagne) ». International Newsletter on Rock Art (INORA), 29, pp. 15-19.

SANCHIDRIÁN TORTI, José L.; MÁRQUEZ ALCÁNTARA, Ana M. 2003: "Radiodataciones y sus repercusiones en el arte prehistórico mala- 
gueño". Mainake, XXV, pp. 275-292.

SANCHIDRIÁN TORTI, José L.; MEDINA ALCAIDE, María Á.; LIÑÁN BAENA, Cristina; ROSAL PADIAL, Yolanda; DEL COBOS PASTOR, José M.; RUIZ-MÁRQUEZ, Rosa; TORRES RIESGO, Antonio. 2017: "Regreso a la cueva de El Morrón (Torres, Jaén): Revisión arqueológica treinta y cinco años después de su descubrimiento". Munibe Antropologia-Arkeologia, 68(6), pp. 85-100. https://doi.org/10.21630/ maa.2017.68.02.

SANTIAGO PÉREZ, Antonio; GILES PACHECO, Francisco; GILES GUZMÁN, Francisco; GUTIÉRREZ LÓPEZ, José M.; FINLAYSON, Clive; FINLAYSON, Geraldine 2010: "Las puntas ligeras de proyectil de los niveles solutrenses de Gorham's Cave, Gibraltar". En E. MATA (ed.): Cuaternario y arqueología: homenaje a Francisco Giles Pacheco, pp. 147-158. Asociación Profesional del Patrimonio Histórico-Arqueológico de Cádiz. Cádiz.

SANTIAGO VÍLCHEZ, José M. 1990: "Avance al estudio del arte parietal Paleolítico de la Cueva de la Motilla". Zephyrvs, XLIII, pp. 65-76.

SIMÓN VALLEJO, María D.; CORTÉS SÁNCHEZ, Miguel; FINLAYSON, Geraldine; GILES PACHECO, Francisco; RODRÍGUEZ-VIDAL, Joaquín; CALLE ROMÁN, Lidia; GUILLAMET, Eudald; FINLAYSON, Clive. 2018: "Hands in the dark: Palaeolithic rock art in Gorham's Cave (Gibraltar)". SPAL. Revista de Prehistoria y Arqueología de La Universidad de Sevilla, 27, pp. 15-28. https://doi.org/10.12795/spal.2018i27.14.

SIMÓN VALLEJO, María D.; CORTÉS-SÁNCHEZ, Miguel; CALLE-ROMÁN, Lidia; PARRILLA-GIRÁLDEZ, Rubén; FINLAYSON, Clive; GILES-PACHECO, Francisco; FINLAYSON, Geraldine; RODRÍGUEZ VIDAL, Joaquín; MARTÍNEZ AGUIRRE, A. 2019. "Martin's Cave a New Palaeolithic Rock Art Site at Gibraltar". En I. SCHMIDT, J. CASCALHEIRA, N. BICHO y G. C. WENIGER (eds.): Human Adaptations to the Last Glacial Maximum. The Solutrean and its Neighbors, pp. 477-490. Cambridge Scholar Pubishing. Cambridge.

SLIMAK, Ludovic; FIETZKE, Jean; GENESTE, Jean Michael; ONTAÑÓN, Roberto. 2018. "Comment on "U-Th dating of carbonate crusts reveals Neandertal origin of Iberian cave art." Science, 361(6408), eaau1371. https://doi. org/10.1126/science.aau1371.

SMITH, Philip Edward L. 1966: Le Solutréen en
France. Delmas. Bordeaux.

SOLER MAYOR, Begoña. 2001: “Técnicas de perforación para la fabricación de colgantes". En V. VILLAVERDE (ed.): De neandertales a cromañones. El inicio del poblamiento humano en tierras valencianas, pp. 383-386. Universidad de Valencia. Valencia.

STRAUS, Lawrence Guy. 2015: "The human occupation of southwestern Europe during the Last Glacial Maximum: Solutrean cultural adaptations in France and Iberia". Journal of Anthropological Research, 71, pp. 465-492.

STRAUS, Lawrence Guy. 2018: "The Upper Paleolithic of Iberia". Trabajos de Prehistoria, 75, pp. 9-51. https://doi.org/10.3989/ tp.2018.12202.

TIFFAGOM, Marc. 2005: "El Solutrense de facies ibérica o la cuestión de los contactos transmediterráneos (Europa, África) en el Último Máximo Glaciar". En J. L. SANCHIDRIÁN, A. M. MÁRQUEZ y J. M. FULLOLA (eds.): IV Simposio de Prehistoria Cueva de Nerja. La Cuenca Mediterránea durante el Paleolítico Superior, 38.000-10.000 años, pp. 60-77. Fundación Cueva de Nerja. Málaga.

TORO, Isidro; ALMOHALLA GALLEGO, Marciano. 1979: "Industrias del Paleolítico superior en la provincia de Granada". Cuadernos de Prehistoria de La Universidad de Granada, 4, pp. 1-20.

TORO, Isidro; ALMOHALLA, Marciano. 1985: "Descubrimiento de industrias del Paleolítico Superior en la provincia de Granada. El yacimiento solutrense de la Cueva de los Ojos (Cozvíjar, Granada)". XVII Congreso Nacional de Arqueología, pp. 97-104.

TORRES NAVAS, Concepción; BAENA PREYSLER, Javier; MORGADO RODRÍGUEZ, Antonio; LOZANO RODRÍGUEZ, J. Antonio; ALCARAZ-CASTAÑO, Manuel. 2012: "Un enclave Solutrense en las Cordilleras Béticas occidentales: la Cueva de Higueral-Guardia (Cortes dela Frontera, Málaga)". Espacio, Tiempo y Forma. Serie I, Prehistoria y Arqueología, t-5, pp. 223-233. https://doi.org/10.5944/etf i.5.4766.

UTRILLA MIRANDA, Pilar. 1994: "Campamentos-base, cazaderos y santuarios. Algunos ejemplos del Paleolítico peninsular". En J. A. LASHERAS (ed.): Homenaje al Dr. Joaquín González Echegaray, pp. 97-113. Ministerio de Cultura, Dirección General de Bellas Artes y Archivos. Museo y Centro de Investigación de 
Altamira. Monografías, 17. Madrid.

VEGA TOSCANO, Luis Gerardo. 1990: "La fin du Paléolithique moyen récent au sud de L'Éspagne (ses implications dans le contexte de la Péninsule Ibérique)“. En C. FARIZY (ed.): Actes du Colloque International de Nemours. Mémoire du Musée de Préhistoire de l'Ile de France, 3, A.P.R.A.I.F, pp. 169-176.

VILLAVERDE, Valentín; ROMAN, Didac. 2015: “El Gravetiense de la vertiente mediterránea ibérica: estado de la cuestión y perspectivas". En C. DE LAS HERAS, J. A. LASHERAS, A. ARRIZABALAGA y M. DE LA RASILLA (eds.): Pensando el Gravetiense: nuevos datos para la región cantábrica en su contexto peninsular y pirenaico, pp. 34-54. Secretaría General Técnica. Centro de Publicaciones. Ministerio de Educación, Cultura y Deporte. Madrid.

WAECHTER, John D'A. 1951: "Excavations at Gorham's Cave, Gibraltar". Proceedings of the Prehistoric Society, 17(01), pp. 83-92. https:// doi.org/10.1017/S0079497X00018806.

WAECHTER John D'A. 1964: "The excavations at Gorham's Cave, Gibraltar, 1951-1954". Bulletin of the Institute of Archaeology, 4, pp. 189221.

WHITE, Randall; BOSINSKI, Gerhard; BOURRILLON, Raphaelle; CLOTTES, Jean; CONKEY, Margaret W.; CORCHON RODRIGUEZ, Soledad; CORTES SÁNCHEZ, Miguel; DE LA RASILLA VIVES, Marco; DELLUC, Brigitte; DELLUC, Gilles; FERUGLIO, Valerie; FLOSS, Harald; FOUCHER, Pascal; FRITZ, Carole; FUENTES, Oscar; GARATE, Diego; GONZÁLEZ, Jesús; GONZÁLEZ-MORALES, Manuel R.; GONZALEZ-PUMARIEGA SOLIS, María; GROENEN, Marc; JAUBERT, Jacques; MARTINEZ-AGUIRRE, María Aranzazu; MEDINA ALCAIDE, María Ángeles; MORO ABADIA, Oscar; ONTAÑ́́N PEREDO, Roberto; PAILLET-MAN-ESTIER, Elena; PAILLET, Patrick; PETROGNANI, Stephane; PIGEAUD, Romain; PINÇON, Genevieve; PLASSARD, Frederic; RIPOLL LOPEZ, Sergio; RIVERO VILA, Olivia; ROBERT, Eric; RUIZ-REDONDO, Aitor; RUIZ LOPEZ, Juan F.; SAN JUAN-FOUCHER, Cristina; SANCHIDRIÁN TORTi, Jose Luis, SAUVET, Georges; SIMON-VALLEJO, María Dolores; TOSELLO, Gilles; UTRILLA, Pilar; VIALOU, Denis; WILLIS, Mark D. 2019: "Still no archaeological evidence that Neanderthals created Iberian cave". Journal of Human Evolution, Volume 144 (July 2020), 102640. ht- tps://doi.org/10.1016/j.jhevol.2019.102640. ZAZO, Caridad; GOY, José Luis. 1988: "Jerez de la Frontera. Hojas 1.048". Mapa Geológico de España. Serie Magna. I.G.M.E., Madrid.

ZILHÃO, João. 1994: "La séquence chrono-stratigraphique du Solutréen portugais". Férvedes, 1, pp. 119-29.

ZILHÃO, João; AUBRY, Thierry; ALMEIDA, Francisco. 1999: «Un modèle technologique pour le passage du Gravettien au Solutréen dans le Sud-Ouest de l'Europe. Les Faciès Leptolithiques du Nord-Ouest Méditerranéen ». XXIV Congres Prehistorique de France - Carcassonne 26-30 septembre 1994 - Les faciès leptolithiques du nord-ouest méditerranéen : milieux naturels et culturels, pp. 165-183. Carcassonne.

ZILHÃO, João. 2000: "The Ebro Frontier: A Model for the Late Extinction of Iberian Neanderthals." En C. B. STRINGER, R. N. E. BARTON, y C. FINLAYSON (eds.): Neanderthals on the Edge, pp. 111-1121. Oxbow Books. Oxford.

ZILHAO, João. 2006: "Chronostratigraphy of the Middle-to-Upper Paleolithic Transition in the Iberian Peninsula." Pyrenae, 1(1), pp. 7-84.

ZILHÃO, João; DAVIS, Simon J. M.; DUARTE, Cidalia; SOARES, Aantonio M. M.; STEIER, Peter; WILD, Eva. 2010: "Pego do Diabo (Loures, Portugal): "Dating the emergence of anatomical modernity in Westernmost Eurasia". PLoSONE, 5 (1). https://doi.org/10.1371/journal. pone. 0008880 .

ZILHÃO, João; ANESIN, Daniela; AUBRY, Thierry; BADAL, Ernestina; CABANES, Dan; KEHL, Martin; KLASEN, Nicole; LUCENA, Armando; MARTÍN-LERMA, Ignacio; MARTÍNEZ, Susana; MATIAS, Henrique; SUSINI, Davide; STEIER, Peter; WILD, Eva; ANGELUCCI, Diego E.; VILLAVERDE, Valentín; ZAPATA, Josefiña. 2017: "Precise dating of the Middle-to-Upper Paleolithic transition in Murcia (Spain) supports late Neandertal persistence in Iberia". Heliyon, 3(11), e00435. https://doi.org/10.1016/j.heliyon.2017.e00435. 